\title{
MODELOS DE PREVISÃO E ESPACIALIZAÇÃO DAS ÁREAS INUNDÁVEIS EM MONTENEGRO, RIO GRANDE DO SUL, BRASIL
}

\section{FORECASTING AND SPATIAL MODELS OF FLOOD AREAS IN MONTENEGRO, RIO GRANDE DO SUL STATE, BRAZIL}

\author{
Guilherme Garcia de Oliveira \\ Universidade Federal do Rio Grande do Sul - Centro Estadual de Pesquisas em Sensoriamento Remoto e Meteorologia \\ - Avenida Bento Gonçalves, 9500 - Campus do Vale - Agronomia - CEP: 91501-970 - Porto Alegre, RS, Brasil- \\ e-mail:g.g.oliveira10@gmail.com
}

Laurindo Antonio Guasselli

Universidade Federal do Rio Grande do Sul - Centro Estadual de Pesquisas em Sensoriamento Remoto e Meteorologia - Avenida Bento Gonçalves, 9500 - Campus do Vale - Agronomia-CEP: 91501-970 - Porto Alegre, RS, Brasil -

e-mail: laurindo.guasselli@ufrgs.br

Dejanira Luderitz Saldanha

Universidade Federal do Rio Grande do Sul - Centro Estadual de Pesquisas em Sensoriamento Remoto e Meteorologia - Avenida Bento Gonçalves, 9500 - Campus do Vale - Agronomia - CEP: 91501-970 - Porto Alegre, RS, Brasil -

e-mail: dejanira.saldanha@ufrgs.br

\section{Informações sobre o Artigo}

Data de Recebimento:

$19 / 01 / 2012$

Data de Aprovação: $14 / 04 / 2013$

\section{Palavras-chave:}

Enchentes; Geoprocessamento; Sensoriamento Remoto.

\section{Keywords:}

Floods; Geoprocessing; Remote Sensing.

\begin{abstract}
Resumo
O objetivo deste estudo foi gerar modelos para a previsão e a espacialização das áreas inundáveis em Montenegro, RS, Brasil, a partir de dados hidrológicos, topográficos e de sensoriamento remoto, e da aplicação de ferramentas de geoprocessamento. Foram utilizados dados de duas estações fluviométricas para elaborar um modelo matemático de previsão das inundações baseado na relação das cotas em eventos de alta magnitude. Para a espacialização e a análise das áreas inundáveis, foi realizada a modelagem da superfície através de curvas de nível com equidistância de $1 \mathrm{~m}$ e pontos cotados, compatíveis com escala de 1:2.000. O modelo aplicado à espacialização das inundações em Montenegro considerou o desnível existente na lâmina d'água durante as inundações. Foram utilizados uma imagem de satélite de alta resolução espacial e plantas do zoneamento urbano para identificar os tipos de uso e ocupação do solo mais afetados por inundações. O modelo matemático de previsão de inundações em Montenegro apresentou precisão submétrica para a estimativa de cotas, obtendo resíduo médio de $0,25 \mathrm{~m}$. Quanto ao modelo de espacialização das inundações, o erro planimétrico médio verificado foi de $9 \mathrm{~m}$ e o erro altimétrico médio (diferença entre as lâminas d'água medida e modelada), nos pontos avaliados, foi de apenas $0,15 \mathrm{~m}$.
\end{abstract}

\section{Abstract}

The purpose of this study was to generate models for forecasting and spatialization of flood areas in Montenegro, RS, Brazil, from hydrological, topographical and remote 
sensing data's, and the application of geoprocessing tools. We used hydrological data from two gauging stations to develop a mathematical model for flood forecasting based on the relationship of quotas in large floods. It was performed a surface model by contours with interval of $1 \mathrm{~m}$ and elevation points for the spatialization and analysis of flood areas, compatible with the scale of 1:2,000. The model applied to the spatialization of floods in Montenegro considered the existing gap in water depth during flooding. We used a high-resolution satellite image and an urban zoning map to identify the land use and land cover most affected by floods. The mathematical model for flood forecasting in Montenegro presented estimated quotas with submeter accuracy, obtaining average residual of $0.25 \mathrm{~m}$. The planimetric root mean occurred on spatialization model of floods was $9 \mathrm{~m}$ and the altimetric root mean (difference between the water depths measured and modeled), in measured points, was only $0.15 \mathrm{~m}$.

\section{Introdução}

As inundações estão entre os desastres naturais mais devastadoras do mundo, levando a prejuízos econômicos e sociais superiores a qualquer outro desastre (Anisoara et $a l .$, 2010). Esses eventos são os mais frequentes, dentre os desastres naturais observados no Brasil.

Ao ocupar as áreas de várzeas fluviais, o homem enfrenta sérios problemas com o regime natural dos rios, em que periodicamente verifica-se a ocorrência de eventos extremos como as inundações. Os municípios ribeirinhos sofrem uma série de impactos negativos nas cheias, quando a água dos rios avança sobre as cidades, ocorrendo danificações em equipamentos públicos, a paralisação de atividades econômicas, a contaminação por doenças de veiculação hídrica, perdas materiais e, em casos extremos, até humanas.

$\mathrm{Na}$ área de estudo deste trabalho, o município de Montenegro, localizado no Estado do Rio Grande do Sul (RS), Brasil, às margens do rio Caí, as inundações ocorrem periodicamente, deixando graves consequências em todos os âmbitos da sociedade. Estima-se que, em média, a área urbana de Montenegro seja atingida pelas águas a cada 1,5 anos. As três maiores inundações observadas, ordenadas pela magnitude, foram as de 1941, 2007 e 1982. Na mais recente, em 2007, mais de 5.000 pessoas foram afetadas, o que ocasionou perdas de grande proporção em todos os setores da economia. Foram danificados também bens patrimoniais, itens do sistema viário, entre outros gêneros de primeira necessidade.

O aperfeiçoamento dos sistemas de previsão de inundações e o mapeamento das áreas atingidas são medidas essenciais para o planejamento de municípios que se desenvolvem junto aos rios, e enfrentam problemas semelhantes ao município de Montenegro. Essas medidas amenizam os danos decorrentes das inundações. Além disso, os mapas de inundação subsidiam a reorganização do espaço urbano, uma vez que podem ser úteis para o estabelecimento de novas diretrizes de ocupação em uma cidade.

A maior dificuldade para a implementação desses sistemas está relacionada à escassez e precariedade dos equipamentos e materiais necessários para essas medidas (estações fluviométricas e pluviométricas, dados topográficos, etc.). Em muitas bacias hidrográficas do Brasil, a disponibilidade de dados hidrológicos é insuficiente para a elaboração de estudos e pesquisas que subsidiem as medidas preventivas.

Por outro lado, alguns materiais estão cada vez mais disponíveis e acessíveis para a utilização em trabalhos relacionados às inundações, compensando parcialmente a escassez dos dados mencionados no parágrafo anterior. Como exemplo, pode-se citar os dados obtidos por sensoriamento remoto, os Sistemas de Informações Geográficas (SIGs) e as ferramentas de geoprocessamento.

A observação por meio de satélites é uma das maneiras mais efetivas e econômicas de estudar alguns fenômenos da natureza, e permite coletar dados para modelar alterações tanto no meio natural quanto no construído (Jensen, 2000). Aliados ao sensoriamento remoto, as técnicas de geoprocessamento e os SIGs surgem como recursos dinâmicos que ampliam a capacidade de mapeamento e de análise, principalmente em virtude dos avanços computacionais, que permitem armazenar e analisar uma quantidade cada vez maior de informações geográficas. A combinação desses recursos permite monitorar e simular os eventos decorrentes das cheias, contribuindo com a leitura e compreensão desses fenômenos.

Nesse contexto, o objetivo geral deste estudo foi gerar modelos para previsão e espacialização das áreas inundáveis em Montenegro, RS, Brasil, a partir de dados hidrológicos, topográficos e de sensoriamento remoto, e da aplicação de ferramentas de geoprocessamento.

\section{Revisão Teórica}

\section{Atividades Humanas e Inundações: Impactos e Medidas Preventivas}

Inundações são eventos extremos, que possuem baixa frequência de ocorrência e alta magnitude, geralmente com elevado poder de destruição, e que acarreta sérios prejuízos para a sociedade. Estão sempre associados a períodos de alta pluviosidade, quando os cursos 
d'água recebem uma quantidade muito elevada de água (período de cheias), superior à capacidade de drenagem do leito menor.

Esses eventos ocorrem naturalmente em todos ambientes fluviais, sendo importantes na manutenção da dinâmica hidrológica e dos processos geomorfológicos. No entanto, mesmo que tenham suas origens em processos naturais, as inundações podem ser potencializadas pelas atividades humanas. Tanto no meio rural, quanto no meio urbano, o homem produz uma série de alterações na superfície terrestre, que implicam na modificação do ciclo hidrológico, como o desflorestamento, a impermeabilização do solo, a canalização dos rios, entre outras (Tucci \& Bertoni, 2003; Eckhardt, 2008). Geralmente, em um sistema mais preservado, a água tem maior percentual de infiltração e interceptação pela cobertura vegetal, levando um tempo maior para atingir os canais fluviais, diminuindo assim os picos de cheia e os riscos de uma inundação mais repentina (Vitte \& Guerra, 2004).

Outra problemática envolvendo a relação das atividades humanas e o regime fluvial diz respeito à ocupação das áreas de risco de inundações. A ocupação humana no leito maior dos rios ocorre em virtude das inundações terem uma distribuição irregular ao longo dos anos (via expansão irregular das áreas urbanas e especulação imobiliária). O tempo transcorre, a memória se dissipa, e a população habita as áreas inundáveis desconsiderando os riscos.

Se as planícies de inundação fossem preservadas ou conservadas, de modo a garantir a permanência da água nesses locais, os episódios de inundações não teriam desfechos alarmantes e catastróficos como observados cotidianamente. Para minimizar os efeitos das inundações seria necessário aumentar a retenção de água nas bacias, através do aumento da infiltração, e da preservação e recuperação das áreas naturais de inundação, localizadas no leito maior.

O planejamento adequado das áreas de risco de inundação e a melhoria dos sistemas de previsão e alerta são as medidas que mais contribuem para a melhor convivência do homem com eventos extremos, uma vez que estes não podem ser controlados. Essas medidas reduzem os prejuízos e danos causados pelas cheias à sociedade. Para o planejamento adequado das áreas de risco de inundação, uma ação imprescindível é o mapeamento das áreas suscetíveis a esses eventos. Os mapas de inundação subsidiam a reorganização do espaço urbano e podem ser utilizadas no estabelecimento de novas diretrizes de ocupação, culminando no planejamento adequado das áreas de risco de inundação, de modo a regular novos empreendimentos, remover gradualmente a ocupação e recuperar as áreas desocupadas (Tucci \& Bertoni, 2003; Vitte \& Guerra, 2004; Eckhardt, 2008).
O aperfeiçoamento dos sistemas de previsão e de alerta de inundações à população constitui-se numa medida de extrema utilidade para os órgãos públicos responsáveis pela remoção e deslocamento dos moradores das áreas que serão atingidas por inundações. De modo geral, para uma previsão de inundação ser eficiente, em curto prazo ou em tempo real, é necessária a instalação de redes telemétricas que coletem e transmitam dados de precipitação e de nível e vazão dos rios, durante o evento.

O município de Montenegro ainda não possui um modelo de previsão de inundações, tão pouco um sistema de alerta de enchentes. Atualmente, a previsão é realizada empiricamente, com base em informações disponibilizadas por moradores de municípios à montante. Os órgãos competentes da prefeitura são informados dos locais inundados à montante e estabelecem uma relação com a possível área de inundação em Montenegro. Esse tipo de estimativa do alcance das águas pode ser eficiente em alguns episódios, mas apresenta sérias limitações, que estão associadas à baixa confiabilidade das informações obtidas (baseadas em relatos pessoais), à restrita dimensão espacial da previsão (realizada pontualmente, onde já se tem uma relação confiável com o nível observado à montante) e à ausência de fundamentação matemática e estatística, o que impossibilita estabelecer um nível de confiança e obter margens de erro.

A previsão matemática de enchentes e inundações pode ser realizada, basicamente, a partir de dados hidrológicos, como a precipitação na bacia hidrográfica, a vazão e a cota dos rios. No local de interesse da previsão é necessário um conhecimento prévio da dinâmica hidrológica (série histórica de vazão ou de cotas). Os dados referentes à precipitação são fundamentais para alimentar os sistemas de previsão que se baseiam na relação entre a intensidade e duração das chuvas e o seu reflexo na vazão do rio, como nos modelos hidrológicos chuva-vazão apresentados em Vörösmarty et al. (1991), Burnash (1995) e Collischonn (2001).

Além dos modelos que convertem matematicamente a chuva em vazão, existem outros métodos de previsão hidrológica de enchentes, os quais podem até ser combinados com os modelos chuva-vazão. O método mais conhecido é o de propagação de vazões, no qual a previsão de vazão é realizada com base em informações de vazão e/ou de nível à montante da seção de interesse. Outro método é o da relação cota-cota, em que a previsão de inundação leva em consideração a cota atingida numa seção à montante do rio (Eckhardt, 2008).

Nos dois primeiros métodos (modelos chuva-vazão e de propagações de vazões) é necessário estabelecer uma confiável relação entre os valores de vazão e o nível atingido no rio, sendo este último, um parâmetro muito importante 
para a previsão da área a ser atingida. Os valores de vazão isolados, isto é, sem relação com a cota a ser atingida pelas águas, não permitem identificar as áreas que serão atingidas pelas águas.

Já nos modelos matemáticos de previsão de inundações baseados na relação cota-cota, o aspecto mencionado no parágrafo anterior é evitado, reduzindo, de certa forma, o percentual de erros associados às estimativas. Bons resultados da aplicação deste tipo de modelagem são apresentados em Eckhardt (2008) para a previsão de inundações no município de Lajeado, RS. O estudo de Eckhardt (2008) propõe um modelo matemático baseado nas séries históricas de duas estações fluviométricas, uma em Lajeado e a outra à montante. A cota estimada à jusante é obtida por uma regressão, na qual se identifica a função de melhor ajuste dos dados.

O tempo de antecedência nesse tipo de previsão é proporcional à distância entre as estações, ou seja, quanto maior a distância, maior a antecedência. No entanto, a precisão do modelo decresce consideravelmente à medida que aumenta a distância entre as mesmas. Logo, necessita-se conciliar os dois aspectos (antecedência e qualidade), de modo a viabilizar o uso do modelo nos planos de remoção e evacuação durante os eventos de grande magnitude.

Quanto aos equipamentos e materiais necessários para a aplicação deste método de previsão de inundações em sistemas de alerta, destacam-se as estações hidrológicas de monitoramento contínuo da precipitação, da vazão e da cota - estações telemétricas -, que permitem o acompanhamento da enchente em tempo real; e as séries históricas de vazão ou de cotas. As séries históricas são fundamentais para a elaboração do modelo matemático, e as estações telemétricas, para o monitoramento dinâmico do nível do rio.

\section{Sensoriamento Remoto e Geoprocessamento no Estudo de Inundações}

O sensoriamento remoto tem-se revelado muito útil para estudos hidrológicos e geomorfológicos em todo mundo (Smith, 1997). Muitas metodologias já foram testadas para se estimar a vazão e o transporte de sedimentos, para compreender a evolução dos padrões de drenagem e para delimitar as áreas mais suscetíveis às inundações com a utilização desses dados. Na elaboração de mapas de inundação comumente se observa a utilização de imagens orbitais, modelos digitais de elevação (MDEs), dados hidrológicos e informações físicas da bacia, como hidrografia, declividades, solos e vegetação nativa, entre outras.

A utilização de imagens de satélite multiespectrais na elaboração de mapas de inundação foi verificada em diversas obras científicas. Esse tipo de dado geralmente é integrado com outros materiais para conferir maior precisão nos mapeamentos (imagens de radar, MDEs e dados hidrológicos). Dentre as plataformas orbitais mais utilizadas, destacam-se Landsat TM e ETM, MODIS e NOAA. Como exemplos do uso de imagens Landsat para o estudo de inundações, podem-se mencionar os trabalhos de Lougeay et al. (1994), Townsend \& Walsh (1998) e Qi et al. (2009).

Em Townsend \& Walsh (1998), por exemplo, é apresentada a integração entre os dados Landsat e de radar Japonese Earth Resource Satellite (JERS-1) para delimitar a extensão máxima das inundações na várzea fluvial do rio Roanoke, na Carolina do Norte, Estados Unidos. No trabalho de Qi et al. (2009), foram agregados dados Shuttle Radar Topography Mission (SRTM) e registros de nível de uma estação hidrológica às imagens Landsat para o mapeamento de inundações. Ambos os estudos concluem que o uso desses dados é eficaz para a análise das áreas com potencial de ocorrência de inundações.

No estudo de Anisoara et al. (2010) o mapeamento das áreas inundadas foi realizado com dados MODIS, em um evento ocorrido em 2006, em Danúbio, na Romênia. Os dados FORMOSAT 2 e SPOT 4 foram utilizados para aumentar a precisão do mapeamento e para validar a lâmina d'água extraída com os dados MODIS. Nesse trabalho, é destacada a vantagem de utilizar dados MODIS pela possibilidade de monitorar os eventos extremos quase em tempo real.

No entanto, o mapeamento das áreas inundáveis através de imagens de satélite, pode ser inviabilizado em virtude da curta duração do pico dos eventos e da alta nebulosidade associada ao período de inundação. Além disso, a baixa resolução temporal da maior parte das plataformas orbitais dificulta ainda mais a delimitação precisa do limite do extravasamento das águas.

A questão da nebulosidade pode ser minimizada utilizando imagens de radar para o mapeamento das áreas de inundação. Bons exemplos da aplicação desse tipo de material são observados em Imhoff et al. (1987), Alsdorf et al. (2000), Brivio et al. (2002) e Rosenqvist \& Birkett (2002). Porém, o uso de imagens de radar não permite o monitoramento dinâmico do regime fluvial, aspecto importante para a elaboração de medidas vinculadas à previsão de inundações e de áreas afetadas. As imagens de radar só permitem a identificação da área inundada de um determinado evento se a imagem for adquirida no período de pico da inundação. Além disso, com esse tipo de dado, não é possível conhecer a área de inundação caso um evento futuro tenha outra magnitude (Eckhardt, 2008).

Desse modo, para se obter bons resultados a respeito da dinâmica das inundações, reforça-se a aplicação de modelos hidrológicos distribuídos para simular o escoamento superficial e a utilização de modelos digitais de 
elevação, os quais permitem identificar as áreas inundadas a cada nível de elevação das águas de um determinado curso d'água. Os estudos de Garrote \& Bras (1995), Bates et al. (1997), Horritt \& Bates (2002), Dutta et al. (2003), Costelloe et al. (2003), Overton (2005) e Kafle et al. (2006) apresentam bons exemplos da aplicação de modelos hidrológicos em estudos relacionados com as enchentes e inundações.

Os trabalhos de Bates et al. (1997), Horritt \& Bates (2002), Costelloe et al. (2003) e Kafle et al. (2006) apresentam modelos hidrológicos distribuídos com a integração de dados obtidos por sensoriamento remoto, nos Estados Unidos, no Reino Unido, na Austrália e no Nepal, respectivamente. Em Horritt \& Bates (2002) são testados alguns modelos hidrológicos em uma extensão de $60 \mathrm{~km}$ do rio Severn. Utilizaram dados de radar adquiridos em eventos de cheias em $1998 \mathrm{e}$ 2000 para calibrar e validar os modelos, além de registros de vazão. Obteve-se bons resultados, principalmente, com a utilização do HEC-RAS e TELEMAC-2D. Costelloe et al. (2003), por exemplo, utiliza registros de medições em estações fluviométricas e imagens de satélite para calibrar o modelo hidrológico proposto. De forma diferente, Kafle et al. (2006) utilizou dados de sensoriamento remoto na geração um modelo de elevação de alta precisão para espacializar as áreas de inundação e a extensão do extravasamento do rio nos períodos em que foi difícil se obter imagens do pico de cheia.

Em Overton (2005) foi apresentado o desenvolvimento de um modelo aplicado à espacialização de inundações utilizando um SIG, dados de sensoriamento remoto e um modelo hidrológico. O estudo de caso foi realizado no rio Murray, na Austrália. No artigo, conclui-se que o uso de ambiente SIG permite a previsão dos impactos na infraestrutura, a estimativa das áreas atingidas e uma análise quantitativa da extensão da inundação, dando suporte para a tomada de decisões por parte dos órgãos competentes.

A utilização de dados de elevação como fonte primária de informação para o mapeamento de áreas inundáveis também é observada em diversos trabalhos. Nesta revisão, foram destacados os seguintes estudos: Bates \& De Roo (2000), Marks \& Bates (2000), Yang \& Rystedt (2002), Bates et al. (2003), Schult \& Pinheiro (2003), Haile \& Rienties (2005) e Eckhardt (2008).

No estudo de Bates \& De Roo (2000), a modelagem das áreas de inundação do rio Meuse, na Holanda, foi desenvolvida a partir de MDEs de alta resolução espacial. Os dados de radar foram utilizados para a validação do mapa de inundação. Foram usadas imagens SAR do pico de uma inundação de grande magnitude. Os resultados obtidos foram satisfatórios, apresentando $82 \%$ de concordância com o observado na realidade.
Em Marks \& Bates (2000) e Bates et al. (2003) observam-se a utilização de dados LIDAR (Airborne Scanning Laser Altimetry) para simulação de inundações baseado em informações topográficas detalhadas. Nesses estudos, verifica-se a integração desses dados topográficos de alta resolução espacial com modelos de inundação em áreas de várzea.

No estudo de Schult \& Pinheiro (2003), foram elaboradas cartas de inundação para o município de Blumenau, em Santa Catarina. As cartas foram elaboradas a partir de um mapa plani-altimétrico na escala 1:2.000, com equidistância das curvas de nível de 1 metro. Neste trabalho, foram levantadas as cotas de inundação das marcas observadas na enchente ocorrida em agosto de 1984, totalizando 879 pontos ao longo da cidade. $\mathrm{O}$ traçado da inundação não seguiu uma cota única (definindo uma linha plana), mas sim as diferentes cotas atingidas pela água nos pontos visitados em campo, formando um plano inclinado, igual ao da linha da água na inundação. Este tipo de mapeamento é bastante complexo (exige pontos amostrais de campo), e representa com maior fidelidade o avanço da água sobre a área urbana.

A metodologia de mapeamento apresentada em Schult \& Pinheiro (2003) é utilizada também em Eckhardt (2008), no rio Taquari, RS. No entanto, neste último, em virtude do represamento do rio por uma barragem à jusante do posto fluviométrico utilizado, foi considerada uma cota única de inundação para todo município (a água avança de forma plana sobre a cidade). Assim como no estudo anterior, Eckhardt (2008) utiliza um MDE de alta resolução para modelar as áreas atingidas pelas inundações. Os dados altimétricos foram conjugados com dados fluviométricos para a geração de um modelo cartográfico aplicado ao mapeamento dessas áreas no município de Lajeado. Os resultados obtidos no trabalho foram amplamente satisfatórios, com precisão planimétrica de mapeamento avaliada em poucos metros.

\section{Materiais e métodos}

\section{Área de Estudo}

O município de Montenegro localiza-se nas coordenadas $29^{\circ} 41^{\prime} \mathrm{S}$ e $51^{\circ} 28^{\prime} \mathrm{W}$, no baixo curso do rio Caí, no Estado do Rio Grande do Sul, Brasil. De acordo com o Instituto Brasileiro de Geografia e Estatística, sua área é de $420 \mathrm{~km}^{2} \mathrm{e}$ a população em 2007 era de 56.790 habitantes. Destes, cerca de $90 \%$ residiam na área urbana do município. Na Figura 1 observa-se a localização da bacia do rio Caí, dos principais cursos d'água, do município de Montenegro e das estações fluviométricas com os registros de nível que foram utilizados neste estudo. Na Figura 2 é apresentado o modelo digital de elevação, da mesma área, a partir de dados SRTM. 


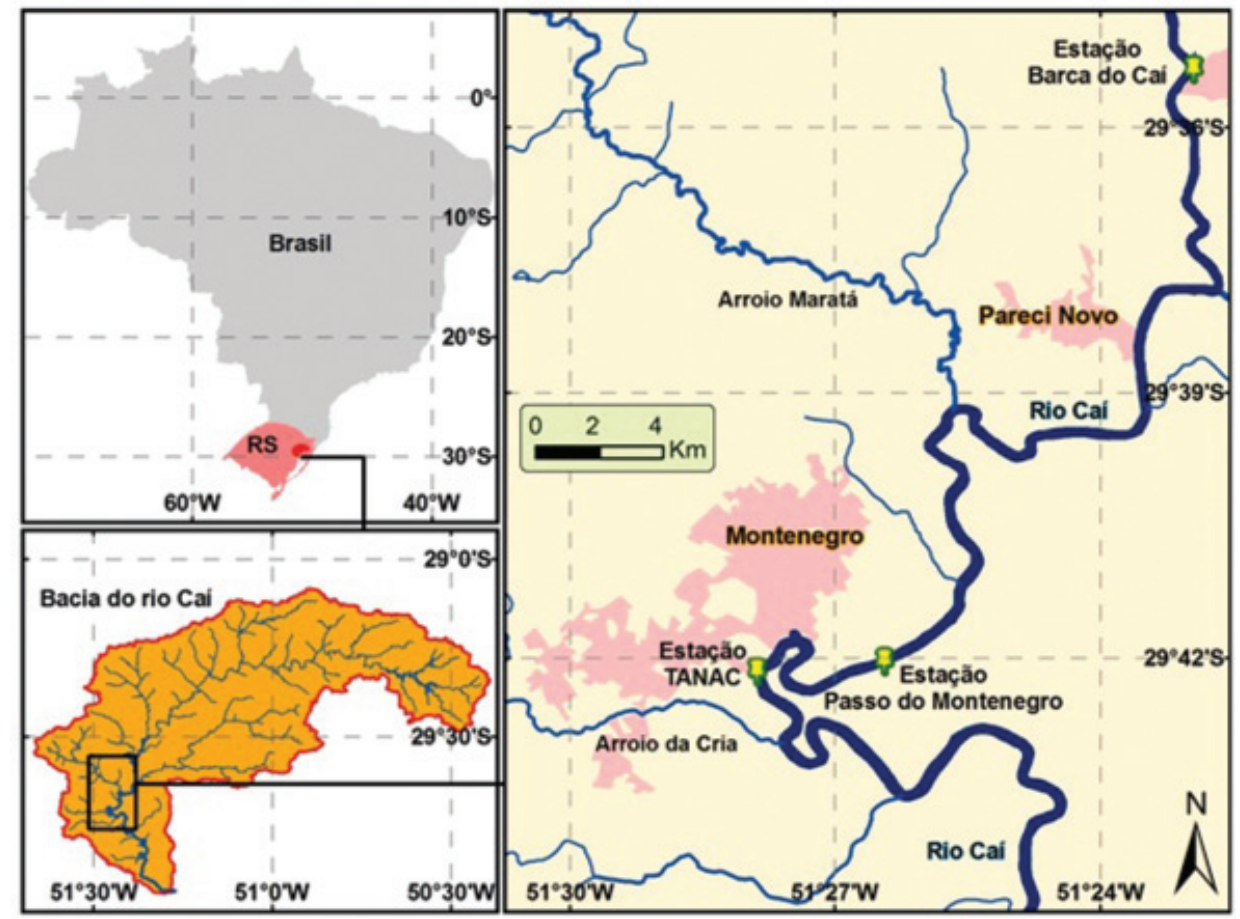

Figura 1 - Localização do município de Montenegro, bacia hidrográfica do rio Caí, RS, Brasil.
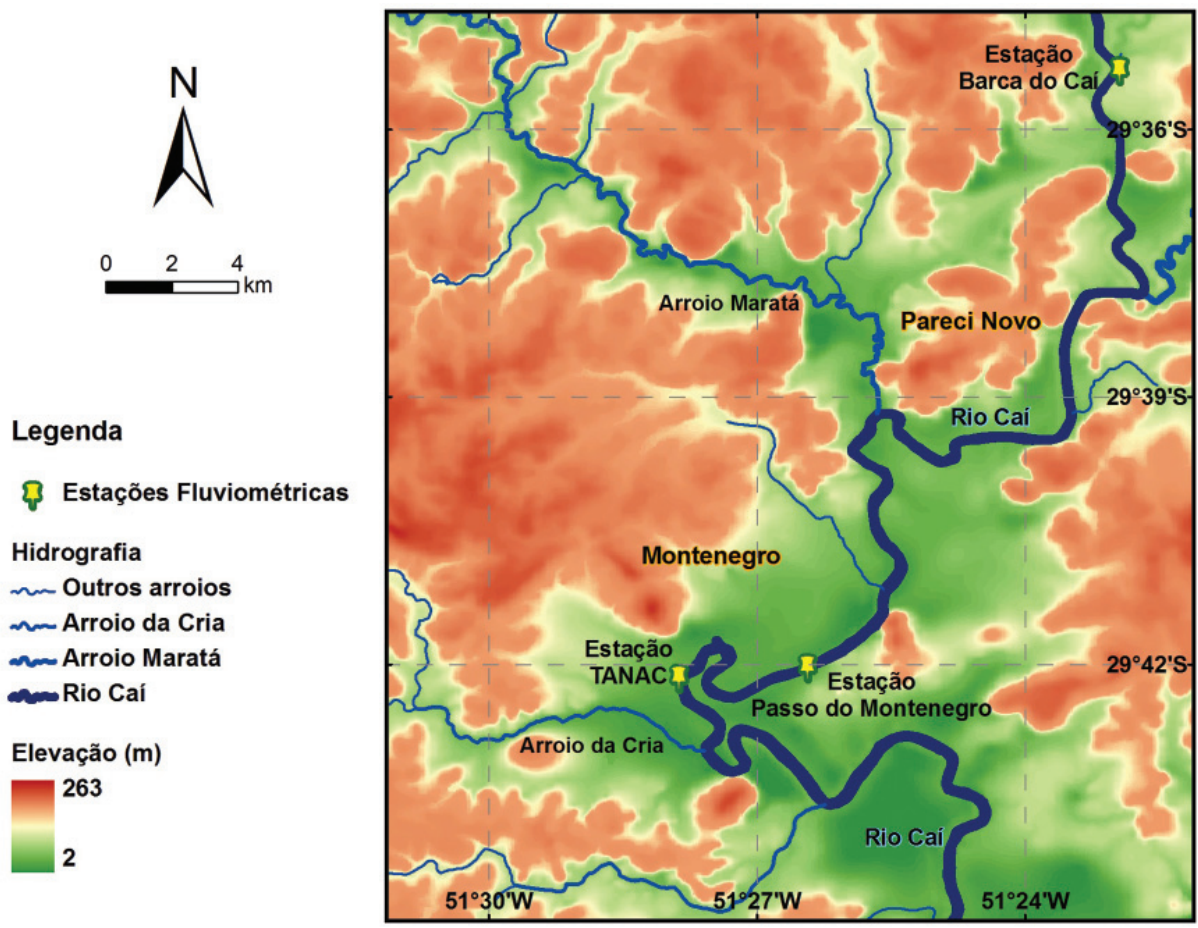

Figura 2 - Mapa altimétrico de Montenegro, bacia hidrográfica do rio Caí, RS, Brasil. 
Quanto à geologia (Figura 3), observa-se em Montenegro, nas áreas mais planas e sujeitas às enchentes, dois tipos de depósitos, ambos do Holoceno (Cenozoico): a) depósitos aluviais, com areia grossa a fina, cascalho e sedimento sílticoargiloso, tanto nas calhas dos rios, quanto nas planícies de inundação; b) depósitos colúvio-aluviais, conglomerados, siltitos e lamitos maciços, ou com laminação plano-paralela e estratificação cruzada acanalada (CPRM, 2006). Além destes depósitos, nas áreas com altitudes intermediárias, são observadas formações areníticas do Jurássico, Mesozoico (Formação Botucatu), e do Permiano, Paleozoico (Formações Pirambóia e Rio do Rasto). Nas áreas mais elevadas, são encontradas feições geológicas da formação Serra Geral, do Cretáceo, Mesozoico (Fácies Gramado), caracterizada por derrames basálticos granulares finos a médio, intercalados com o arenito Botucatu (CPRM, 2006).

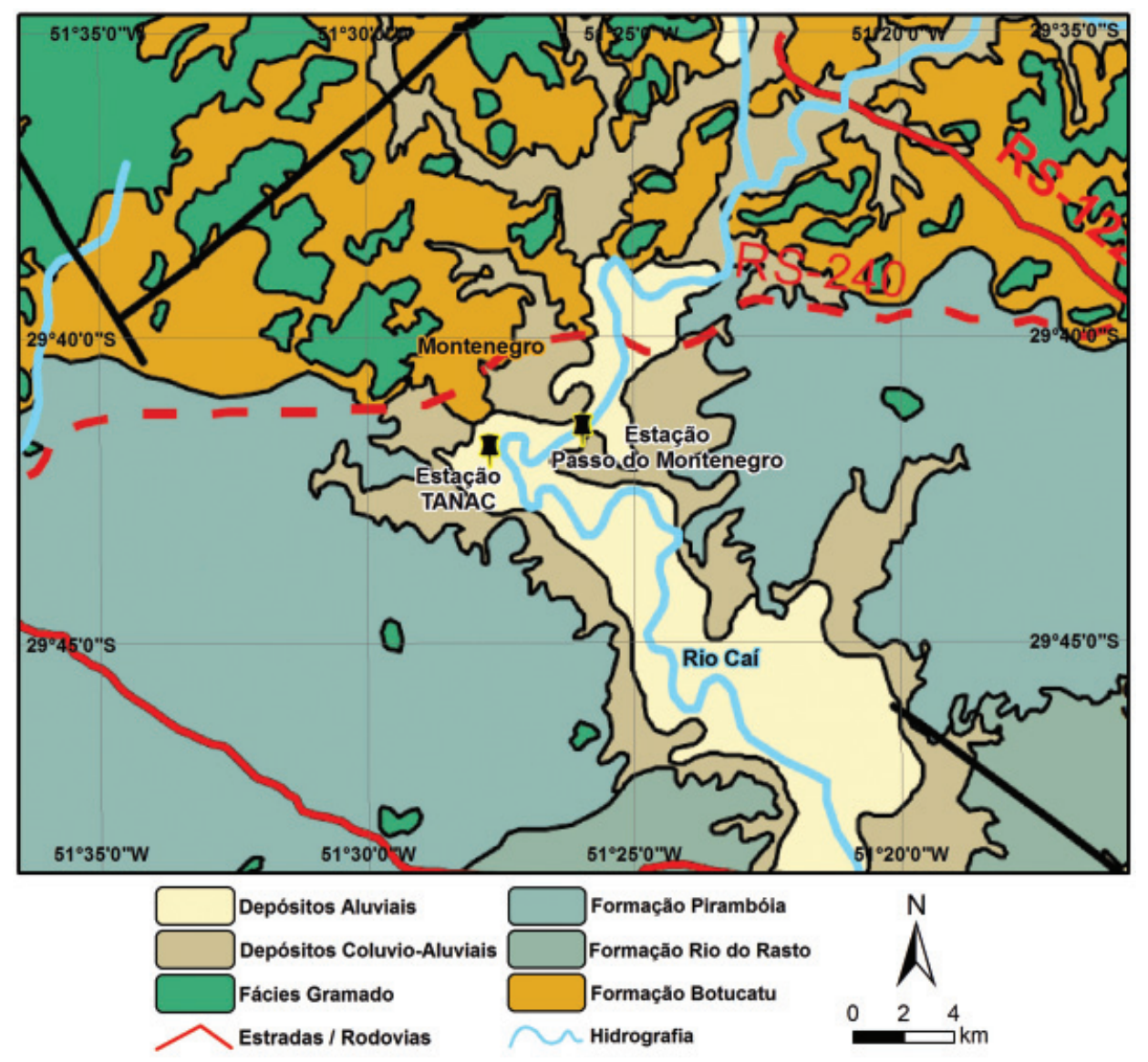

Figura 3 - Mapa geológico de Montenegro, bacia hidrográfica do rio Caí, RS, Brasil.

As áreas mais planas e baixas, referentes aos depósitos sedimentares, pertencem à Unidade Geomorfológica (UG) das Planícies Alúvio-Coluvionares. Tratam-se de modelados de acumulação em terraços fluviais ou colúvios com depósitos de enxurradas, ambos com média a forte predisposição à erosão, com ruptura de declive em relação ao leito do rio (IBGE, 2003). Nas áreas de altitude intermediária, a UG característica é a da Depressão do Rio Jacuí, com formas de relevo de colinas e morros com topos convexos, com densidade de drenagem muito grosseira, com médio a forte aprofundamento das incisões. Nestas áreas, verifica-se a presença de muitos morros testemunhos (formações areníticas). Já nas áreas mais elevadas, predomina a UG dos Patamares da Serra Geral, com formas de relevo em morros com topos tabulares, com média predisposição à erosão, densidade de drenagem grosseira e forte aprofundamento das incisões, com algumas linhas de escarpa erosiva bem delimitadas (IBGE, 2003).

A distância entre os postos fluviométricos Barca do Caí e Passo do Montenegro é de 20,2km, com desnível de sete metros, indicando uma baixa declividade de $0,035 \%$. Neste trecho do rio Caí, a largura média do canal é de 50 metros e da planície de inundação é de $2,5 \mathrm{~km}$. Entre os 
dois postos existe um grande aporte lateral de água (bacia complementar), com área de $1.345 \mathrm{~km}^{2}$, cujas principais drenagens são o rio Cadeia e o arroio Maratá. A área de drenagem da bacia de contribuição ao posto Barca do Caí é de $2.991,8 \mathrm{~km}^{2}$, enquanto que a bacia referente ao posto Passo do Montenegro possui $4.337 \mathrm{~km}^{2}$. No trecho do rio Caí que corta a cidade de Montenegro a largura média do rio é um pouco maior, variando entre 55 e 75 metros, com largura da planície de inundação variando entre 3 e $3,5 \mathrm{~km}$.

\section{Materiais utilizados}

Foram utilizados os seguintes materiais: a) dados fluviométricos: série histórica de cotas das estações Passo do Montenegro (Montenegro) e Barca do Caí (no município de São Sebastião do Caí); b) tabelas de controle do nível do rio Caí, de hora em hora, na régua instalada na TANAC S.A, em Montenegro; c) plantas cadastrais (escala 1:2.000) restituídas e desenhadas em 1991, a partir de levantamento aerofotogramétrico (escala 1:8.000) realizado em 1989; d) dados SRTM; e) imagem de satélite QuickBird ortorretificada; f) planta de zoneamento de uso e ocupação do solo de Montenegro, atualizada em 2004; g) receptor de sinal GPS.

\section{Cálculo dos Tempos de Retorno e Avaliação da Sazonalidade das Cheias em Montenegro}

A fim de evitar erros grosseiros no cálculo do tempo de retorno (TR) das cheias - o período que decorre entre duas cheias de igual magnitude -, foram ignorados os anos com registros incompletos. O cálculo compreende a seleção do evento de maior magnitude em cada ano da série, o ordenamento dos eventos conforme a magnitude (ranking), dos valores mais elevados para os menores, e a aplicação da seguinte equação (1):

$$
\mathrm{R}=\frac{\mathrm{N}+1}{\mathrm{M}}
$$

Onde: TR é o tempo de retorno; $\mathrm{N}$ é o número total de eventos considerados na série; $\mathrm{M}$ é o número de ordem (ranking) que representa a posição da cheia na escala organizada.

Após o cálculo do TR das cheias, realizou-se a análise da distribuição sazonal para verificar os períodos do ano com maior recorrência desses eventos. Visando obter resultados mais confiáveis, trabalhou-se apenas com os anos cujos registros estavam completos.

\section{Modelo Matemático de Previsão de Enchentes e Inundações}

O modelo de previsão de inundações para Montenegro baseou-se na relação cota-cota entre os registros de duas estações fluviométricas (uma no local de interesse, em Montenegro, e a outra, à montante, em São Sebastião do Caí). A previsão do nível do rio à jusante (estação Passo do Montenegro) é realizada com base no nível medido (pico da inundação) à montante, na estação Barca do Caí. A distância entre as estações é de $20,2 \mathrm{~km}$ e o atraso (entre os picos) varia entre 12 e $16 \mathrm{~h}$, de acordo com a intensidade e a duração das chuvas.

O modelo se baseia na relação entre as cotas máximas atingidas nas duas estações em eventos de grande magnitude ao longo da série histórica. A seleção de eventos para o processo da modelagem matemática teve como referência a série da estação Passo do Montenegro e baseou-se em dois critérios: a) o maior evento anual registrado; b) todos os eventos com TR superior a dois anos. Com esses critérios, foi garantida a seleção de, no mínimo, um evento por ano, não descartando nenhum nível de inundação com TR superior a dois anos.

Depois de selecionados os eventos e extraídas as cotas atingidas na estação Passo do Montenegro, foram coletadas as cotas alcançadas, nos mesmos eventos, na estação à montante (Barca do Caí) para verificação da correlação e posterior regressão. Estes foram inseridos no pacote estatístico LabFit, que seleciona uma das centenas de funções de ajuste de curva para os dados. $\mathrm{O}$ algoritmo utilizado para o ajuste foi o Levenberg-Marquardt. O resultado é uma expressão que calcula a cota a ser atingida em Montenegro, em função da cota registrada à montante.

\section{Elaboração do Modelo Digital de Elevação}

Para elaborar o MDE de Montenegro foram utilizadas as plantas cadastrais do município de Montenegro, contendo, entre outras, informações quanto à topografia e hidrografia. A utilização desse material se deve a escala de mapeamento detalhada da área de estudo (1:2.000), na qual se obteve curvas de nível com equidistância de um metro e pontos cotados com precisão submétrica.

Essas plantas foram disponibilizadas em meio analógico, o que implicou no processo de digitalização e vetorização das informações contidas. A digitalização foi realizada em um scanner e o procedimento de vetorização das plantas digitais no ArcGIS 9.2. Foram criados três arquivos vetoriais: arquivo de ponto para os pontos cotados; arquivo de linha para as curvas de nível; arquivo de linha para a hidrografia. Foram vetorizadas somente as curvas e pontos com elevação inferior a $15 \mathrm{~m}$, tendo em vista que nas cotas superiores não existe risco de inundação. 
A geração do MDE de Montenegro foi realizada a partir da interpolação dos dados vetorizados em escala 1:2.000 e dos dados SRTM, este último utilizado somente nas áreas com elevação superior a $15 \mathrm{~m}$. Deste modo, os dados SRTM foram utilizados em áreas que não estão sujeitas às inundações para garantir que o MDE possua um formato retangular, sob a justificativa de reduzir o tempo de vetorização e de interpolação dos dados.

Nesta etapa, foram testados dois interpoladores: a triangulação (TIN) e o Topo to Raster. O método de interpolação conhecido como TIN é uma adaptação desenvolvida por Peuker et al. (1979) da triangulação de Delaunay. Trata-se de um interpolador exato em que o algoritmo cria triângulos através da ligação dos pontos amostrais, sendo muito eficiente para representar relevos acentuados. Nessa rede irregular de triângulos são armazenados três conjuntos de registros no banco de dados: a lista de nós, a lista de apontadores e a lista de triângulos (Silva, 1999). Este tipo de estrutura (mais complexa) garante que feições lineares do relevo (os cumes e os talvegues) sejam consideradas no processo de geração do MDE. Essas feições são inseridas na modelagem por meio de linhas de quebra, que devem ser obrigatoriamente arestas dos triângulos gerados.

A implementação Topo to Raster trata-se de um método projetado especificamente para a criação de MDEs hidrologicamente coerentes, originado no programa ANUDEM, e disponibilizado no ArcGIS 9.2. O programa foi desenvolvido na década de 1980, e o resultado, apresentado em Hutchinson (1989). O Topo to Raster mescla a eficiência computacional dos interpoladores locais (como o Inverso do Quadrado da Distância) com a continuidade da superfície dos interpoladores globais (como a krigagem e o spline). Trata-se de uma técnica spline discretizada que permite ao MDE representar as mudanças abruptas do terreno, como os rios e os cumes (Wahba, 1990; Hutchinson, 1993). Comumente, ao utilizar essa implementação, inserem-se como dados de entrada: os pontos cotados, as curvas de nível e as linhas de drenagem.

De acordo com os testes, o método de interpolação por triangulação representou de forma mais adequada o terreno em boa parte da área de estudo. O interpolador apresentou problemas pontuais, com a formação de triângulos planos (três pontos de uma única curva), principalmente nos talvegues, onde passam os pequenos arroios. Nesses locais, a implementação Topo to Raster obteve melhor desempenho, basicamente em virtude de suas propriedades que garantem a elaboração de superfícies hidrologicamente coerentes.

Optou-se, assim, pela geração de um MDE híbrido, conciliando as qualidades dos dois interpoladores. Primeiramente, procedeu-se a interpolação por triangulação (TIN). Em seguida, com a inserção dos mesmos dados, fez-se a interpolação pelo Topo to Raster. Depois, foram selecionados todos os triângulos planos obtidos com a primeira interpolação. Nesses locais, foram criados pontos regulares, para os quais foram extraídos os valores de elevação do MDE interpolado pelo Topo to Raster. A partir da inserção desses novos pontos, fez-se a atualização do arquivo TIN. Esse procedimento forçou o algoritmo a não criar triângulos planos.

Como resultado final, obteve-se um MDE de alta precisão altimétrica nas áreas com cotas inferiores a $15 \mathrm{~m}$, e de média precisão nas áreas de entorno. $\mathrm{O}$ arquivo TIN foi convertido para o formato de grade, com resolução espacial de $0,6 \mathrm{~m}$, com a finalidade de tornar a manipulação do modelo mais rápida.

\section{Modelo de Espacialização das Áreas de Inundação por Cota e TR}

Esta etapa compreendeu a espacialização das áreas de inundação por cota (intervalos de $0,5 \mathrm{~m}$ ) e por TR, e a identificação dos tipos de uso e ocupação do solo mais impactados. Os intervalos de TR utilizados foram de 30, 20,10, 5 e 2 anos. Para a identificação dos tipos de uso e ocupação atingidos pelas inundações em diferentes cenários, utilizou-se o zoneamento de uso e ocupação do solo de Montenegro, do Plano Diretor Municipal, atualizado em 2004 por levantamento aerofotogramétrico e trabalhos de campo, e a imagem de satélite QuickBird, adquirida no mesmo ano.

O mapeamento das áreas atingidas por cota e por TR foi gerado de forma automatizada, utilizando um algoritmo que cria um arquivo vetorial compreendendo todas as áreas com cota inferior à desejada, desde que não haja impedimentos para a passagem de água (diques ou barreiras). Foram consideradas diversas cotas de inundação para um mesmo cenário, tornando o modelo mais realista. $\mathrm{O}$ avanço da água sobre a área de estudo não foi plano, isto é, o modelo representou o desnível existente na lâmina d'água no trecho, assim como nas cartas de inundação apresentadas em Schult \& Pinheiro (2003).

Esse aprimoramento da representação do avanço da inundação sobre a cidade de Montenegro foi possível 
através de pontos de controle coletados em diferentes locais, de forma bem distribuída, onde se pôde estimar (através de marcas em paredes; de relatos de moradores; de informações de órgãos públicos) a altura da lâmina da água em duas inundações recentes (2007 e 2008). Após a coleta dos pontos, foi possível, a partir da sobreposição destes com o MDE, verificar que a cota de inundação variava espacialmente. As maiores cotas de inundação foram verificadas à montante da estação Passo do Montenegro, e as menores à jusante da estação. Esses pontos foram interpolados pelo Inverso do Quadrado da Distância, processo que originou uma superfície de variação na cota de inundação. Ao cruzar essa superfície com o MDE, obteve-se um modelo normalizado capaz de reproduzir o avanço da água de forma mais realista e complexa.

A avaliação do modelo de espacialização das áreas de inundação foi realizada a partir dos pontos coletados em campo que não foram utilizados no processo de criação da superfície de variação da cota de inundação. Todo posicionamento foi realizado a partir de GPS.

\section{Simulação da Inundação Ocorrida em Setembro de 2007}

A última etapa do trabalho consistiu em simular a inundação ocorrida no período entre 22 e 29 de setembro de 2007, com pico na madrugada do dia 25, em Montenegro. Para esta simulação foram utilizados o modelo de espacialização das áreas de inundação e os dados do controle de nível realizado pela TANAC S.A (com informações de hora em hora do nível da água). As cotas de inundação atingidas na régua da TANAC S.A foram extrapoladas para todo município baseando-se no modelo de variação apresentado no subitem 3.6. Para calibração da simulação também foram consultados os dados da estação Passo do Montenegro, que dispõe de apenas duas leituras por dia.

Na simulação do avanço da água, considerou-se a presença de barreiras e/ou diques que impedem a passagem da água. Isso significa que, para um pixel ser inundado, é necessário que o mesmo tenha uma cota inferior à cota atingida pela água na estação Passo do Montenegro (compatibilizada) e esteja conectado topologicamente à drenagem (sem nenhum impedimento para a passagem da água). Já, na simulação da retração da inundação (redução do nível do rio), as barreiras e diques foram desconsiderados, pois o nível de água acumulada, em locais isolados, reduz em um ritmo mais semelhante ao nível do rio.

\section{Resultados e discussões}

\section{Tempos de Retorno e Distribuição Sazonal das Cheias em Montenegro}

A cota média é de $1,62 \mathrm{~m}$ na régua da estação Passo do Montenegro, em que a maior cota atingida foi de 9,20m (7,58 m acima da média), em maio de 1941, com TR superior a 60 anos. Esta foi a única vez em que a cota de $9 \mathrm{~m}$ foi atingida e ultrapassada pelas águas do rio Caí. De acordo com a Tabela 1, a cota de $8 \mathrm{~m}$ é atingida com recorrência de 5 anos e a cota $7 \mathrm{~m}$ possui TR inferior a 2 anos. Observa-se ainda uma pequena variação da cota $(1 \mathrm{~m})$ entre um evento com mais de 30 anos de TR (8,7m em 2007) e outro com TR de 3 anos (7,7m em 1980).

Tabela 1 - TR das cheias na estação Passo do Montenegro, em Montenegro, RS, Brasil.

\begin{tabular}{|c|c|c|c|c|c|c|c|}
\hline Ano & Cota & Ordem & TR & Ano & Cota & Ordem & TR \\
\hline 1941 & 9.20 & 1 & 63.00 & 1975 & 7.30 & 32 & 1.97 \\
\hline 2007 & 8.70 & 2 & 31.50 & 1953 & 7.24 & 33 & 1.91 \\
\hline 1982 & 8.52 & 3 & 21.00 & 1995 & 7.13 & 34 & 1.85 \\
\hline 1942 & 8.38 & 4 & 15.75 & 1957 & 7.10 & 35 & 1.80 \\
\hline 1965 & 8.32 & 5 & 12.60 & 1977 & 7.08 & 36 & 1.75 \\
\hline 1967 & 8.32 & 6 & 10.50 & 1998 & 7.07 & 37 & 1.70 \\
\hline 2000 & 8.24 & 7 & 9.00 & 1940 & 6.96 & 38 & 1.66 \\
\hline 1956 & 8.20 & 8 & 7.88 & 1945 & 6.92 & 39 & 1.62 \\
\hline 1988 & 8.20 & 9 & 7.00 & 1970 & 6.92 & 40 & 1.58 \\
\hline 1984 & 8.13 & 10 & 6.30 & 1955 & 6.90 & 41 & 1.54 \\
\hline 2003 & 8.05 & 11 & 5.73 & 1994 & 6.88 & 42 & 1.50 \\
\hline 1985 & 8.01 & 12 & 5.25 & 1976 & 6.85 & 43 & 1.47 \\
\hline 1944 & 8.00 & 13 & 4.85 & 1949 & 6.70 & 44 & 1.43 \\
\hline 1954 & 8.00 & 14 & 4.50 & 1947 & 6.65 & 45 & 1.40 \\
\hline 2001 & 8.00 & 15 & 4.20 & 1981 & 6.64 & 46 & 1.37 \\
\hline 1997 & 7.91 & 16 & 3.94 & 1996 & 6.64 & 47 & 1.34 \\
\hline 1987 & 7.90 & 17 & 3.71 & 1974 & 6.52 & 48 & 1.31 \\
\hline 1959 & 7.80 & 18 & 3.50 & 1964 & 6.35 & 49 & 1.29 \\
\hline 1990 & 7.80 & 19 & 3.32 & 1951 & 6.30 & 50 & 1.26 \\
\hline 1963 & 7.70 & 20 & 3.15 & 1999 & 6.28 & 51 & 1.24 \\
\hline 1980 & 7.70 & 21 & 3.00 & 1978 & 6.27 & 52 & 1.21 \\
\hline 2002 & 7.70 & 22 & 2.86 & 1979 & 6.23 & 53 & 1.19 \\
\hline 1983 & 7.62 & 23 & 2.74 & 1946 & 6.20 & 54 & 1.17 \\
\hline 1971 & 7.50 & 24 & 2.63 & 1960 & 6.04 & 55 & 1.15 \\
\hline 1986 & 7.48 & 25 & 2.52 & 1943 & 5.74 & 56 & 1.13 \\
\hline 1973 & 7.45 & 26 & 2.42 & 1950 & 5.50 & 57 & 1.11 \\
\hline 1992 & 7.45 & 27 & 2.33 & 1958 & 5.50 & 58 & 1.09 \\
\hline 1966 & 7.42 & 28 & 2.25 & 1948 & 5.35 & 59 & 1.07 \\
\hline 1972 & 7.40 & 29 & 2.17 & 1968 & 5.26 & 60 & 1.05 \\
\hline 1989 & 7.38 & 30 & 2.10 & 1952 & 4.76 & 61 & 1.03 \\
\hline 1969 & 7.30 & 31 & 2.03 & 1962 & 3.92 & 62 & 1.02 \\
\hline
\end{tabular}

A Figura 4 apresenta o gráfico com as máximas anuais da série histórica da estação Passo do Montenegro, e a linha de tendência por média móvel centrada em um período de cinco anos. Esse gráfico permite analisar a distribuição dos grandes episódios de cheias no transcorrer da série de registros e verificar os períodos com inundações de maiores proporções. 


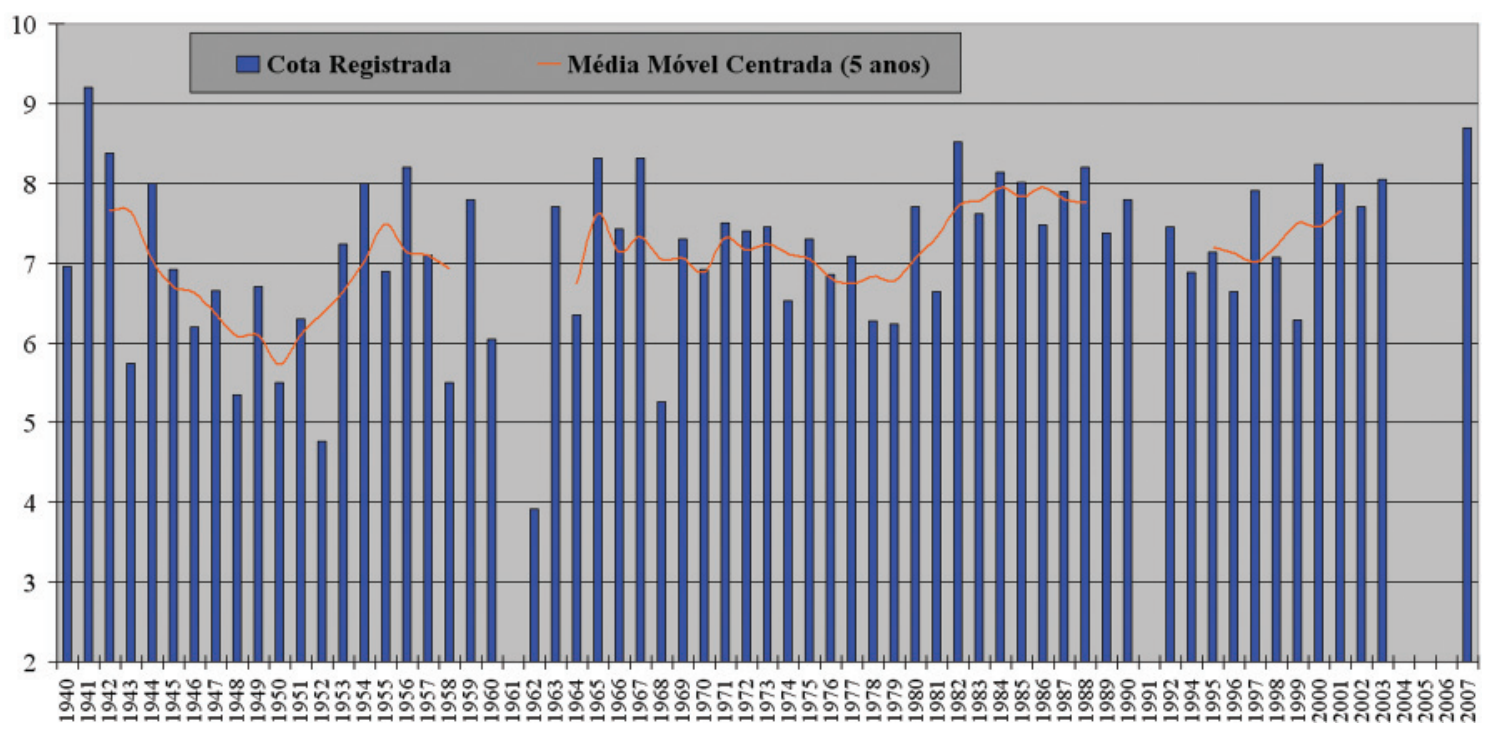

Figura 4 - Cotas máximas anuais na estação Passo do Montenegro, Montenegro, RS, Brasil.

Em Montenegro (Figura 4) não foi verificada uma tendência de crescimento na frequência de eventos de maior magnitude nas últimas décadas. Analisando a média móvel, constataram-se três períodos com cotas máximas mais elevadas (próximas a 8m): entre 1942 e 1943; entre 1982 e 1988; e 2001.

Quanto à distribuição sazonal das cheias ao longo da série histórica, a Tabela 2 revela que há uma concentração entre junho e outubro, representando $79 \%$ das cheias na estação Passo do Montenegro. O mês com maior ocorrência de cheias é junho, totalizando 11 eventos $(17,74 \%)$. O resultado condiz com o esperado, pois corresponde ao período mais chuvoso do ano (INMET, 2009), em que ocorre o predomínio dos sistemas frontais (Wollmann, 2008).

Tabela 2 - Sazonalidade das cheias em Montenegro, RS, Brasil (1940-2007).

\begin{tabular}{ccc}
\hline Mês & Cheias & Proporção \\
\hline Janeiro & 2 & $3.23 \%$ \\
Fevereiro & 1 & $1.61 \%$ \\
Março & 1 & $1.61 \%$ \\
Abril & 2 & $3.23 \%$ \\
Maio & 2 & $3.23 \%$ \\
Junho & 11 & $17.74 \%$ \\
Julho & 10 & $16.13 \%$ \\
Agosto & 9 & $14.52 \%$ \\
Setembro & 9 & $14.52 \%$ \\
Outubro & 10 & $16.13 \%$ \\
Novembro & 1 & $1.61 \%$ \\
Dezembro & 4 & $6.45 \%$ \\
\hline
\end{tabular}

\section{Modelo Matemático de Previsão de Enchentes e Inundações}

O processo da modelagem voltada à previsão de cotas em Montenegro seguiu a metodologia descrita no subitem 3.4. De acordo os critérios estabelecidos, foram selecionados 82 pares de cotas (Passo do Montenegro - Barca do Caí). O coeficiente de correlação dos dados foi de 0,9221 e a função que apresentou o melhor ajuste dos dados, de acordo com o Qui-Quadrado Reduzido, é expressa pela seguinte equação (2) (ver também a Figura 5):

$$
y p=\frac{1}{\left(0.0715^{*}[\mathrm{X}-11.0745] 2+0.9452\right)}+0.5336^{*} X
$$

Onde: Yp é a cota prevista em Montenegro e X é a cota em São Sebastião do Caí.

O coeficiente de determinação $\left(\mathrm{R}^{2}\right)$ da regressão adotada na modelagem foi de 0,894 , indicando um excelente ajuste dos dados. O resíduo médio foi de $0,25 \mathrm{~m}$ e a amostra que apresentou maior discrepância entre o medido e o previsto obteve um erro de $0,83 \mathrm{~m}$.

As Tabelas 3 e 4 apresentam, respectivamente, a síntese das características relacionadas à confiabilidade do modelo matemático, e as cotas previstas para Montenegro nos 82 eventos selecionados. A precisão média do modelo para a previsão de cotas entre $5 \mathrm{~m}$ e $6 \mathrm{~m}$ é de $0,42 \mathrm{~m}$, entre $6 \mathrm{~m}$ e $7 \mathrm{~m}$ é de $0,28 \mathrm{~m}$, entre $7 \mathrm{~m}$ e $8 \mathrm{~m}$ é de $0,23 \mathrm{~m}$ (intervalo com os melhores resultados) e a partir de $8 \mathrm{~m}$ é de $0,42 \mathrm{~m}$. 


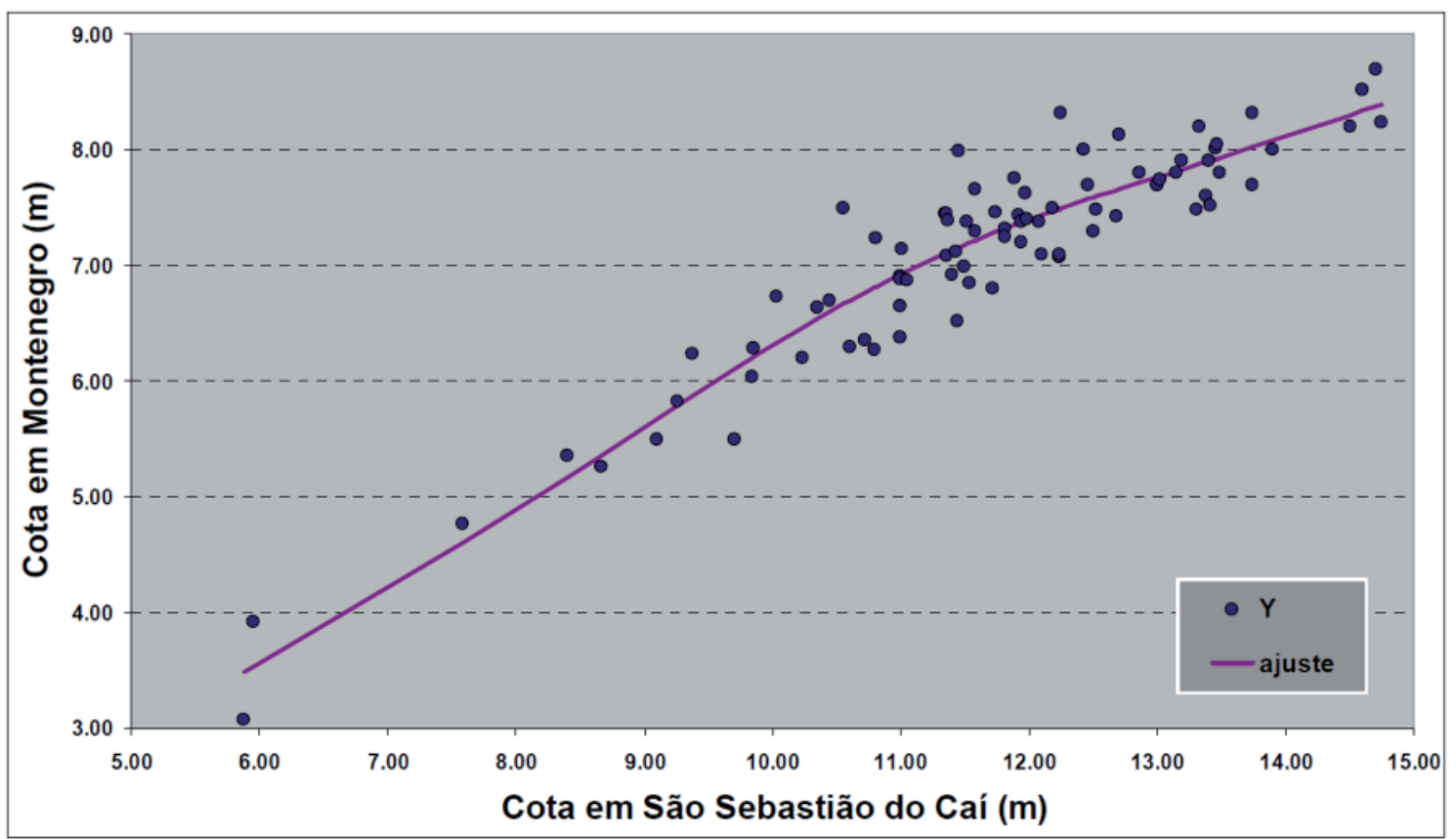

Figura 5 - Linha de ajuste dos dados para previsão de cota do rio Caí em Montenegro.

Tabela 3 - Síntese de características relacionadas à confiabilidade do modelo.

\begin{tabular}{|c|c|}
\hline $\begin{array}{c}\mathrm{R}^{2} \\
\text { Resíduo Médio } \\
\text { Erro Mínimo } \\
\text { Erro Máximo }\end{array}$ & $\begin{array}{l}0.894 \\
0.25 \mathrm{~m} \\
0.00 \mathrm{~m} \\
0.83 \mathrm{~m}\end{array}$ \\
\hline \multicolumn{2}{|c|}{ Faixa de Confiança (95\%) } \\
\hline $\begin{array}{l}\text { Previsão de cotas entre } 5 \mathrm{~m} \mathrm{e} 6 \mathrm{~m} \\
\text { Previsão de cotas entre } 6 \mathrm{~m} \mathrm{e} 7 \mathrm{~m} \\
\text { Previsão de cotas entre } 7 \mathrm{~m} \text { e } 8 \mathrm{~m} \\
\text { Previsão de cotas }>8 \mathrm{~m}\end{array}$ & $\begin{array}{l}\text { de }(Y p-0.210 \mathrm{~m}) \mathrm{a}(\mathrm{Yp}+0.210 \mathrm{~m}) \\
\operatorname{de}(Y p-0.140 \mathrm{~m}) \mathrm{a}(\mathrm{Yp}+0.140 \mathrm{~m}) \\
\operatorname{de}(Y p-0.115 \mathrm{~m}) \mathrm{a}(\mathrm{Yp}+0.115 \mathrm{~m}) \\
\operatorname{de}(Y p-0.210 \mathrm{~m}) \mathrm{a}(\mathrm{Yp}+0.210 \mathrm{~m})\end{array}$ \\
\hline \multicolumn{2}{|c|}{ Precisão do Modelo (95\%) } \\
\hline Previsão de cotas entre $5 \mathrm{~m} \mathrm{e} 6 \mathrm{~m}$ & $0.42 \mathrm{~m}$ \\
\hline Previsão de cotas entre $6 \mathrm{~m} \mathrm{e} 7 \mathrm{~m}$ & $0.28 \mathrm{~m}$ \\
\hline Previsão de cotas entre $7 \mathrm{~m} \mathrm{e} 8 \mathrm{~m}$ & $0.23 \mathrm{~m}$ \\
\hline Previsão de cotas $>8 \mathrm{~m}$ & $0.42 \mathrm{~m}$ \\
\hline
\end{tabular}

De acordo com os dados apresentados na Tabela 4, 78 eventos $(95,12 \%)$ obtiveram resíduo inferior a $0,60 \mathrm{~m}$, sendo que, destes, apenas três apresentaram resíduo superior a $0,45 \mathrm{~m}$. Esses valores indicam que o modelo matemático é bastante eficiente para a previsão de cotas no município de Montenegro.

O maior resíduo $(-0,83 \mathrm{~m})$ foi verificado em três eventos, ocorridos em: 20/09/1967; 17/10/1997; 28/04/2001. Considerando o método utilizado de leitura (manual) e a dificuldade de organização das séries históricas utilizadas, os resultados verificados neste modelo (precisão submétrica para todos os intervalos de previsão) são excelentes.
Tabela 4 - Cotas registradas e previstas na estação Passo do Montenegro, e o resíduo por amostra.

\begin{tabular}{|c|c|c|c|c|c|c|c|c|c|}
\hline Data & $\mathrm{x}$ & $\mathbf{Y}$ & Yp & Resíduo & Data & $\mathbf{x}$ & Y & $\mathrm{Yp}$ & Resíduo \\
\hline $1 / 10 / 1947$ & 11.00 & 6.65 & 6.93 & 0.28 & $16 / 12 / 1979$ & 9.37 & 6.23 & 5.87 & -0.36 \\
\hline $25 / 7 / 1948$ & 8.40 & 5.35 & 5.17 & -0.18 & $31 / 7 / 1980$ & 13.74 & 7.70 & 8.02 & 0.32 \\
\hline $17 / 7 / 1949$ & 10.44 & 6.70 & 6.60 & -0.10 & $24 / 8 / 1980$ & 11.81 & 7.25 & 7.32 & 0.07 \\
\hline 22/9/1949 & 11.00 & 6.38 & 6.93 & 0.55 & $4 / 12 / 1980$ & 13.41 & 7.52 & 7.90 & 0.38 \\
\hline $18 / 10 / 1950$ & 9.70 & 5.50 & 6.10 & 0.60 & 9/6/1981 & 10.35 & 6.64 & 6.54 & -0.10 \\
\hline $20 / 10 / 1951$ & 10.60 & 6.30 & 6.70 & 0.40 & $29 / 6 / 1982$ & 14.60 & 8.52 & 8.34 & -0.18 \\
\hline $30 / 6 / 1952$ & 7.58 & 4.76 & 4.59 & -0.17 & $25 / 6 / 1983$ & 11.81 & 7.32 & 7.32 & -0.00 \\
\hline $3 / 10 / 1953$ & 10.80 & 7.24 & 6.82 & -0.42 & $10 / 7 / 1983$ & 11.92 & 7.44 & 7.36 & -0.08 \\
\hline $22 / 7 / 1954$ & 13.90 & 8.00 & 8.08 & 0.08 & $2 / 8 / 1983$ & 11.97 & 7.62 & 7.38 & -0.24 \\
\hline $23 / 9 / 1954$ & 12.10 & 7.10 & 7.44 & 0.34 & 20/6/1984 & 12.70 & 8.13 & 7.66 & -0.47 \\
\hline $22 / 4 / 1955$ & 11.00 & 6.90 & 6.93 & 0.03 & 14/8/1985 & 13.45 & 8.01 & 7.92 & -0.09 \\
\hline $6 / 4 / 1956$ & 14.50 & 8.20 & 8.30 & 0.10 & $26 / 12 / 1986$ & 12.52 & 7.48 & 7.59 & 0.11 \\
\hline 20/9/1956 & 11.72 & 6.80 & 7.28 & 0.48 & $31 / 7 / 1987$ & 11.37 & 7.39 & 7.12 & -0.27 \\
\hline 9/9/1957 & 12.24 & 7.10 & 7.49 & 0.39 & 14/8/1987 & 13.19 & 7.90 & 7.83 & -0.07 \\
\hline $13 / 6 / 1958$ & 9.10 & 5.50 & 5.67 & 0.17 & 26/9/1988 & 13.33 & 8.20 & 7.88 & -0.32 \\
\hline $23 / 6 / 1959$ & 13.15 & 7.80 & 7.81 & 1 & $25 / 9 / 1989$ & 11.94 & 7.38 & 7.37 & -0.01 \\
\hline $30 / 8 / 1959$ & 13.00 & 7.70 & 7.76 & 0.06 & $13 / 10 / 1990$ & 13.49 & 7.80 & 7.93 & 0.13 \\
\hline $2 / 9 / 1960$ & 9.84 & 6.04 & 6.20 & & $28 / 12 / 1991$ & 10.23 & 6.20 & 6.46 & .26 \\
\hline $6 / 9 / 1961$ & 12.86 & 7.80 & 7.71 & -0.09 & $29 / 5 / 1992$ & 11.43 & 7.12 & 7.15 & 0.03 \\
\hline $1 / 1 / 1962$ & 5.95 & 3.92 & 3.53 & -0.39 & $7 / 7 / 1992$ & 11.36 & 7.45 & 7.11 & -0.34 \\
\hline $16 / 1 / 1962$ & 5.88 & 3.07 & 3.49 & 0.42 & $12 / 7 / 1993$ & 11.51 & 7.38 & 7.18 & -0.20 \\
\hline $12 / 10 / 1963$ & 13.00 & 7.70 & 7.76 & 6 & 26/5/1994 & 11.05 & 6.87 & 6.95 & 0.08 \\
\hline $3 / 9 / 1964$ & 10.72 & 6.35 & 6.77 & 0.42 & $20 / 6 / 1994$ & 11.00 & 6.88 & 6.93 & 0.05 \\
\hline $21 / 8 / 1965$ & 13.74 & 8.32 & 8.02 & -0.30 & $21 / 7 / 1995$ & 11.01 & 7.14 & 6.93 & -0.21 \\
\hline 12/9/1965 & 11.89 & 7.75 & 7.35 & -0.40 & $16 / 10 / 1996$ & 10.03 & 6.73 & 6.33 & -0.40 \\
\hline $21 / 12 / 1966$ & 12.68 & 7.42 & 7.65 & 0.23 & $5 / 8 / 1997$ & 13.40 & 7.91 & 7.90 & -0.01 \\
\hline $20 / 9 / 1967$ & 12.25 & 8.32 & 7.49 & -0.83 & $17 / 10 / 1997$ & 11.45 & 7.99 & 7.16 & -0.83 \\
\hline $8 / 11 / 1968$ & 8.66 & 5.26 & 5.36 & 0.10 & $17 / 8 / 1998$ & 12.23 & 7.07 & 7.49 & 0.42 \\
\hline $20 / 2 / 1969$ & 11.58 & 7.30 & 7.22 & -0.08 & $16 / 10$ & 9.85 & 6.28 & 6.21 & -0.07 \\
\hline $7 / 6 / 1970$ & 11.40 & 6.92 & 7.13 & 0.21 & 000 & 9.26 & 5.82 & 5.79 & -0.03 \\
\hline $17 / 3 / 1971$ & 12.18 & 7.50 & 7.47 & -0.03 & $14 / 10 / 2000$ & 14.75 & 8.24 & 8.39 & 0.15 \\
\hline $15 / 8 / 1971$ & 12.08 & 7.38 & 7.43 & & & 10.55 & 7.50 & 6.67 & -0.83 \\
\hline $20 / 7 / 1972$ & 11.94 & 7.20 & 7.37 & & $22 / 7 / 2001$ & 12.43 & 8.00 & 7.56 & -0.44 \\
\hline $21 / 9 / 1972$ & 11.98 & 7.40 & 7.39 & -0.01 & $14 / 6 / 2002$ & 12.46 & 7.70 & 7.57 & -0.13 \\
\hline 20/9/1973 & 11.35 & 7.45 & 7.11 & -0.34 & 2100 & 13.30 & 7.48 & 7.87 & 0.39 \\
\hline $11 / 6 / 1974$ & 11.44 & 6.52 & 7.15 & 0.63 & $10 / 7 / 2003$ & 13.46 & 8.05 & 7.92 & -0.13 \\
\hline $16 / 9 / 1975$ & 12.50 & 7.30 & 7.59 & 0.29 & $1 / 9 / 2005$ & 11.74 & 7.46 & 7.29 & -0.17 \\
\hline $10 / 8 / 1976$ & 11.54 & 6.85 & 7.2 & & $16 / 10 / 2005$ & 11.58 & 7.66 & 7.22 & -0.44 \\
\hline $3 / 8 / 1977$ & 11.36 & 7.08 & 7.11 & & $11 / 7 / 2007$ & 13.02 & 7.74 & 7.77 & 0.03 \\
\hline $19 / 8 / 1977$ & 11.49 & 6.99 & 7.18 & 0.19 & $25 / 9 / 2007$ & 14.70 & 8.70 & 8.37 & -0.33 \\
\hline $7 / 12 / 1978$ & 10.79 & 6.27 & 6.81 & 0.54 & $27 / 10 / 2008$ & 13.38 & 7.60 & 7.89 & 0.29 \\
\hline
\end{tabular}


A Figura 6 ilustra as tendências do modelo (superestimação e subestimação) em relação à magnitude do evento a ser previsto. Observa-se que o modelo superestima a cota na previsão de eventos de menor magnitude (até $7 \mathrm{~m}$ ) e subestima um pouco a cota em eventos com cotas superiores a $7,5 \mathrm{~m}$.

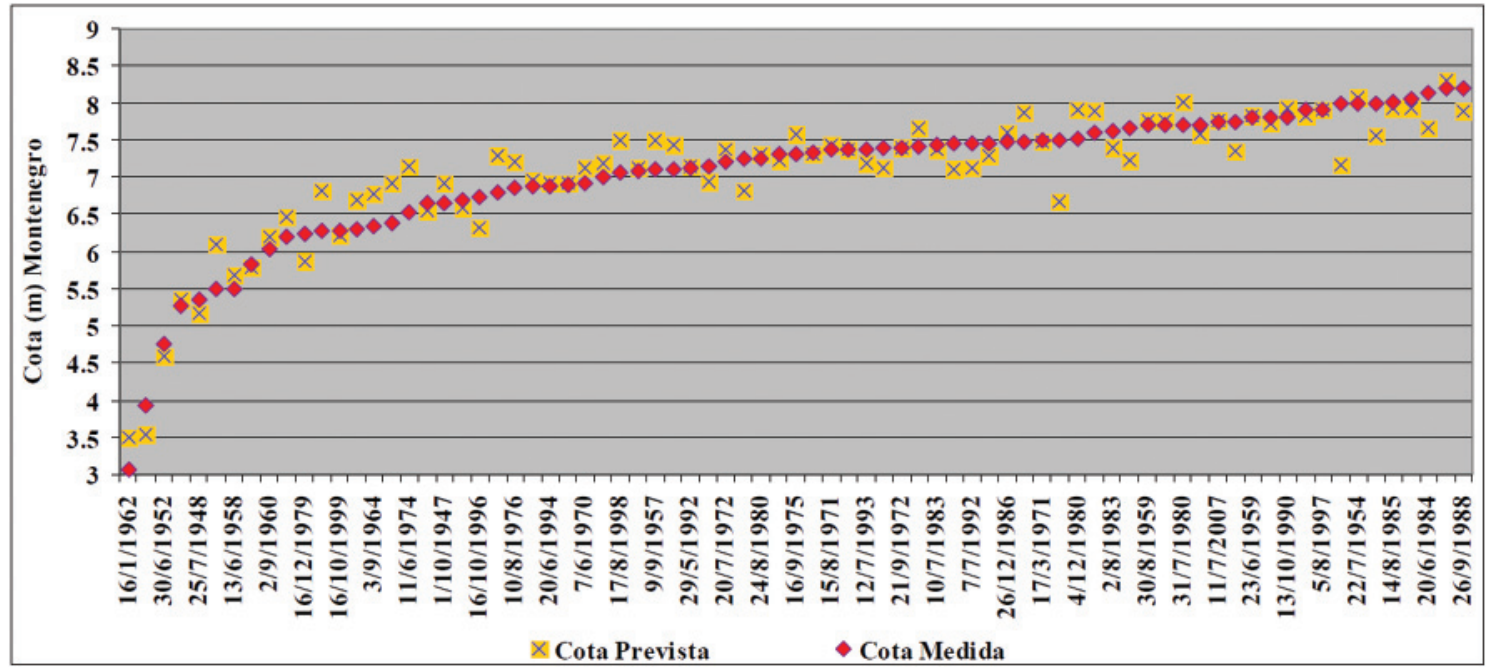

Figura 6 - Tendências do modelo matemático conforme a magnitude.

O tempo de antecedência da previsão de cota máxima em Montenegro é de $12 \mathrm{~h}$ a $16 \mathrm{~h}$. No entanto, salienta-se que esse aspecto não interfere significativamente nas ações de deslocamento e remoção de pessoas e de objetos, uma vez que não é necessário aguardar o pico da cheia em São Sebastião do Caí para iniciar o monitoramento e as simulações de cenários de inundação. À medida que o nível do rio se eleva à montante é possível iniciar a remoção das pessoas das áreas em que a inundação já foi prevista. Além disso, ressalta-se que a inclusão de dados advindos dos novos equipamentos, que estão sendo instalados na bacia hidrográfica do rio Caí, aumentará a confiabilidade do modelo matemático e permitirá monitorar o avanço das águas de forma mais eficiente.

\section{Modelo para Espacialização de Inundações}

Neste subitem, são apresentados os resultados e as discussões referentes ao modelo para espacialização de inundações em Montenegro, RS. Conforme foi descrito no subitem 3.6, esta etapa do trabalho compreendeu a modelagem das áreas de inundação pela cota atingida na estação Passo do Montenegro, em intervalos de $0,50 \mathrm{~m}$, e por TR, e a quantificação dos tipos de uso e ocupação do solo mais impactados pelas inundações.

É importante destacar que a espacialização das áreas inundadas considerou o modelo de elevação normalizado, que tem como referência a estação Passo do Montenegro. A normalização do MDE teve como objetivo representar o desnível existente na lâmina d'água das inundações, e foi obtida pelo cruzamento do MDE inicial com a superfície de variação da lâmina (conforme subitem 3.6).
Após esse processo, dois pixels com a mesma cota normalizada, independente da localização na área de estudo, apresentam a mesma probabilidade de serem inundados. Esse aspecto reduz significativamente o tempo de processamento dos dados para a espacialização das áreas de inundação, sem ignorar as diferentes cotas atingidas pela água, ao longo da área de estudo, em um mesmo evento.

As Figuras 7 e 8 apresentam, respectivamente, as áreas de inundação, na área modelada de Montenegro, pela cota atingida na estação Passo do Montenegro e por tempos de retorno. O intervalo de cotas utilizado no primeiro mapa (Fig. 7) foi de $3 \mathrm{~m}$ a $10 \mathrm{~m}$, valor superior a maior cota já registrada em Montenegro (9,2m em 1941). No segundo mapa (Fig. 8), foram espacializadas as áreas inundação por TR de 30, 20, 10, 5 e 2 anos (cotas 8,70m; $8,50 \mathrm{~m} ; 8,30 \mathrm{~m} ; 8,00 \mathrm{~m} ; 7,30 \mathrm{~m}$, respectivamente).

De acordo com os mapas (Figuras 7 e 8), os bairros mais afetados por inundações são: Tanac, Bairro Municipal, Industrial, Passo do Manduca, Ferroviário e Olaria. Outros bairros também são afetados, mas com menores prejuízos, como o Zootecnia e o São João.

Observa-se que existem três áreas de extravasamento do rio Caí: a) na porção nordeste, área com presença de banhados, onde as águas invadem os bairros Passo do Manduca, Ferroviário e Olaria; b) na porção sul da área modelada, extensa área úmida ao longo do arroio da Cria; c) na porção central, no bairro Industrial. 

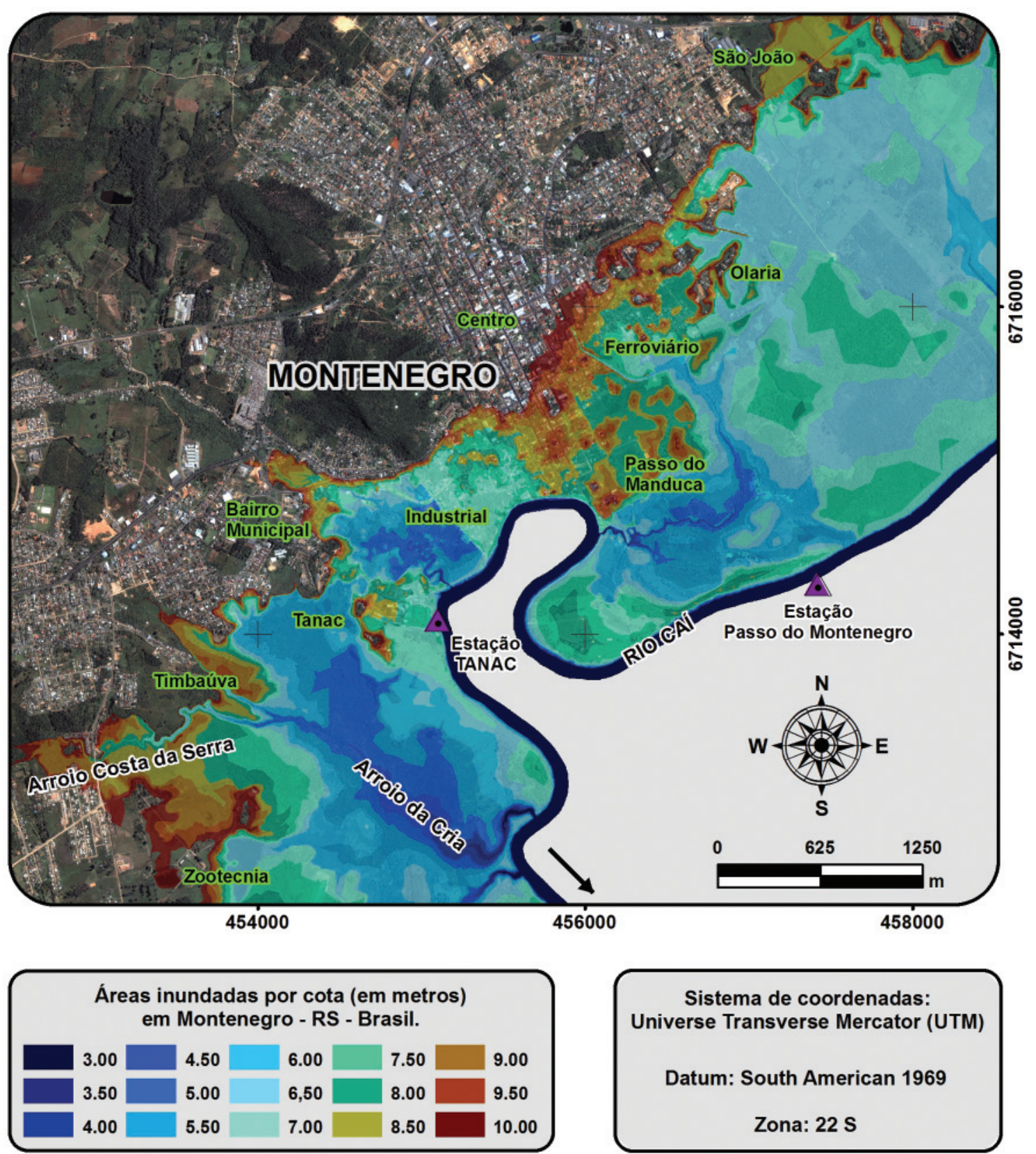

Sistema de coordenadas: Universe Transverse Mercator (UTM)

Datum: South American 1969

Zona: $22 \mathrm{~S}$

Figura 7 - Mapa das áreas inundáveis de Montenegro, RS, Brasil.

A Figura 7 mostra que grande parte da área modelada de Montenegro é atingida por inundações com magnitude inferior a 7,5m na estação Passo do Montenegro. Essa é uma constatação preocupante, uma vez que essa cota é atingida frequentemente, com TR aproximado de 2 anos. Essa característica também é ilustrada pela Figura 8 , na qual fica evidente a predominância de áreas atingidas com recorrência igual ou inferior a 2 anos. Somente na porção central da área modelada, entre os bairros Industrial e Passo do Manduca, é que a extensão da inundação se altera significativamente em eventos com tempos de retorno maiores.
Considerando todos os tipos de uso e ocupação do solo, $\mathrm{a}$ área atingida por inundações aumenta consideravelmente até a magnitude de $8 \mathrm{~m}$, em que aproximadamente 1.147 ha da área modelada ficam tomados pelas águas. Em eventos com magnitude de cota entre $8 \mathrm{~m}$ e $9 \mathrm{~m}$, ocorre um acréscimo moderado de área afetada, e entre a cota $9 \mathrm{~m}$ e $10 \mathrm{~m}$, praticamente não se alteram os locais atingidos pelas águas. Assim, se ocorresse um evento com magnitude superior (até 10m) à registrada em 1941, a dimensão da inundação seria praticamente a mesma. 

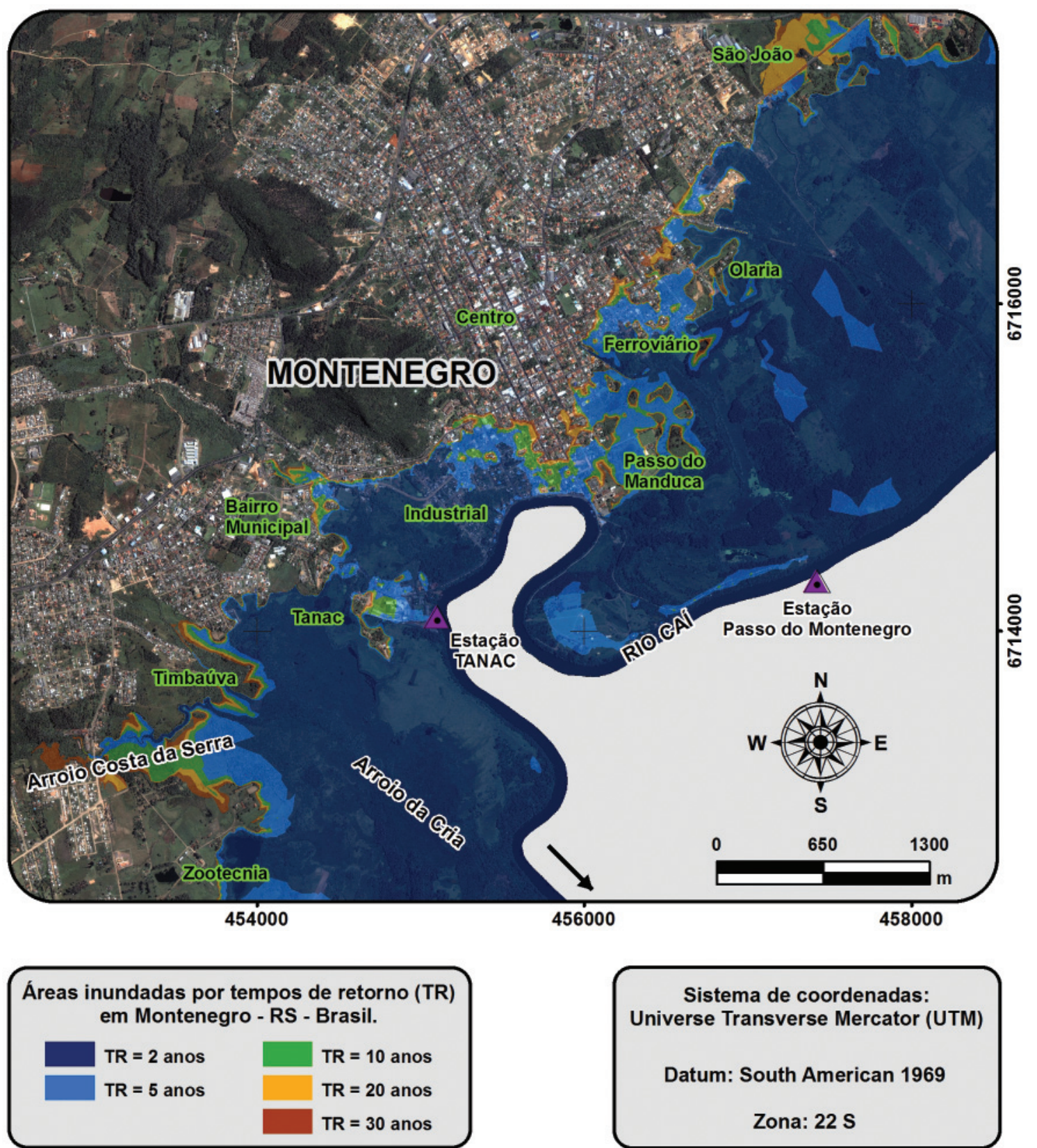

Sistema de coordenadas: Universe Transverse Mercator (UTM)

Datum: South American 1969

Zona: $22 \mathrm{~S}$

Figura 8-Espacialização das áreas inundáveis por TR de Montenegro, RS, Brasil.

A Figura 9 ilustra os tipos de uso e ocupação do solo observados na área de inundação modelada do município de Montenegro, RS. Foram consideradas as seguintes categorias de uso e ocupação do solo: úmidas);

a) Vegetação e banhados (florestas, campos e áreas

b) Uso Rural (cultivos agrícolas, em geral);

c) Uso Urbano, subdividido em cinco classes: áreas de lazer e recreação, residenciais, mistas, comerciais e industriais.
As áreas de vegetação e de banhados correspondem à categoria de uso e ocupação do solo que é mais atingida pelas inundações na área modelada (Fig. 9). Aproximadamente 1.138 ha dessa categoria são atingidos pelas águas, considerando magnitudes inferiores a $10 \mathrm{~m}$. Esse valor representa $80,86 \%$ da área total inundada no modelo. A categoria menos afetada é a de uso rural, com apenas 65 ha $(4,63 \%$ da área total). Estas áreas estão localizadas na porção sudoeste do recorte (Fig. 9). 


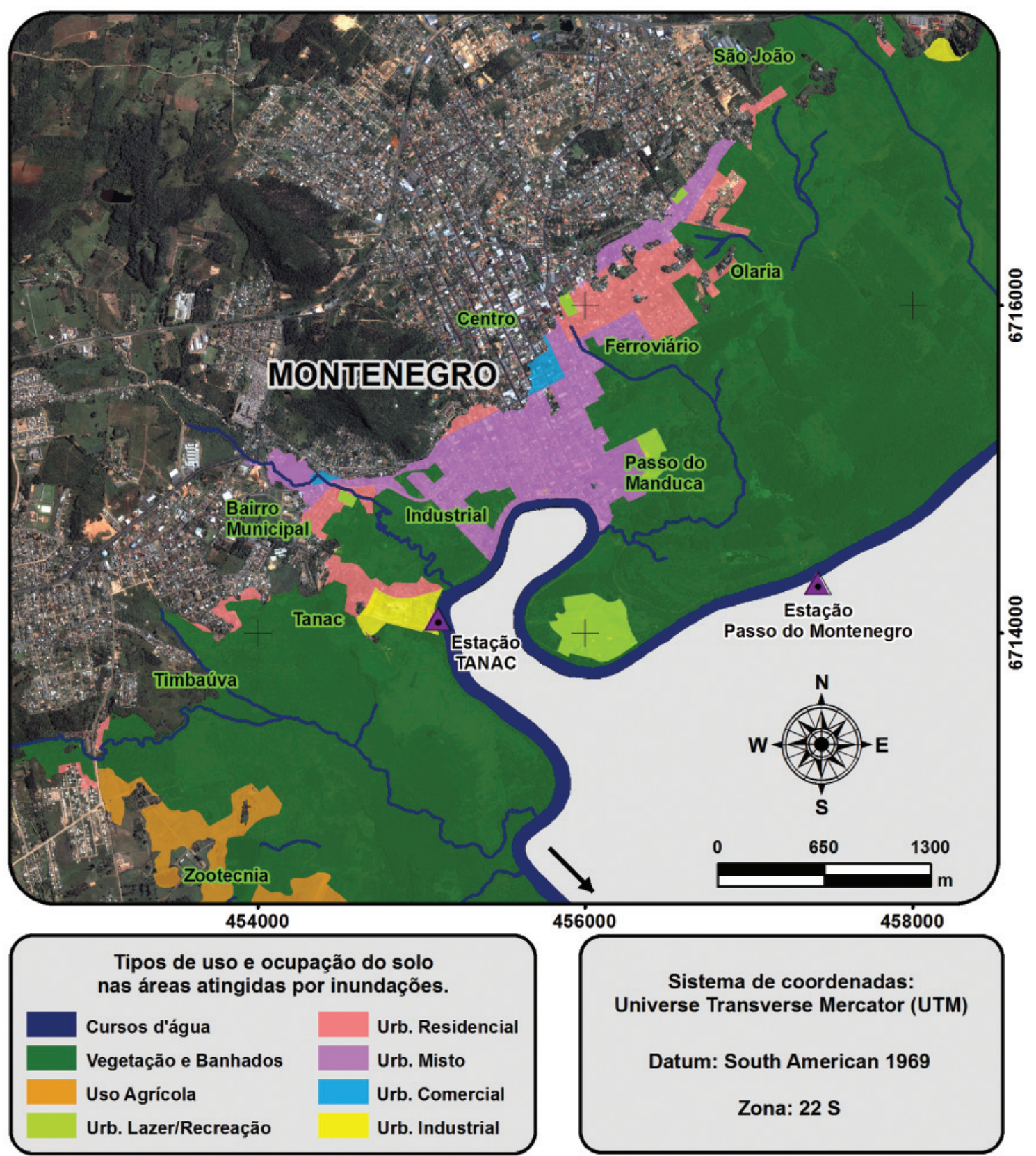

Figura 9 - Uso e ocupação do solo das áreas atingidas por inundações em Montenegro, RS, Brasil.

Quanto ao uso urbano, cerca de 204ha são atingidos por inundações com magnitude de $10 \mathrm{~m}$. Esse valor representa $14,51 \%$ da área total inundada no modelo. Considerando apenas o contexto urbano, destacam-se as categorias de uso misto (109ha) e de uso residencial (58ha) como as mais afetadas. O uso urbano comercial é o que sofre os menores impactos diretos das inundações, com área inundada de aproximadamente 5 ha.
Percebe-se, a partir dos dados apresentados na Tabela 5 , que ocorre um incremento significativo de área atingida por inundações da categoria de vegetação e banhados em eventos de magnitude entre $6 \mathrm{~m}$ e $7 \mathrm{~m}$. Este intervalo de cotas corresponde ao limite superior do leito menor, consistindo assim na cota de extravasamento das águas sobre a planície de inundação. 
O mesmo não ocorre com as áreas de uso urbano, que começam a ser inundadas, substancialmente, em eventos de magnitude de cota igual ou superior a $7 \mathrm{~m}$ em Passo do Montenegro (Tabela 5). Isso se deve ao fato destas estarem localizadas em uma área levemente mais elevada da planície de inundação.

Verifica-se que em eventos de magnitude inferior a 6,5 $\mathrm{m}$, pouco mais de 4 ha de uso urbano ficam inundados. Esse valor aumenta para 29 ha na cota $7 \mathrm{~m}$, 98ha na cota $8 \mathrm{~m}$ e 158 ha na cota $9 \mathrm{~m}$. No evento ocorrido em 25 setembro de 2007 ( simulado neste artigo), que atingiu a cota $8,7 \mathrm{~m}$ em Passo do Montenegro, cerca de 140 ha de uso urbano foram atingidos pela inundação.

Tabela 5 - Uso e ocupação do solo inundado por cota em Montenegro/RS.

\begin{tabular}{|c|c|c|c|c|c|c|c|c|}
\hline \multirow{2}{*}{$\begin{array}{l}\text { Cota } \\
\text { (m) }\end{array}$} & \multicolumn{8}{|c|}{ Área inundada (acumulada) em hectares } \\
\hline & $\begin{array}{l}\text { Vegetação e } \\
\text { Banhados }\end{array}$ & Rural & $\begin{array}{l}\text { Urb. Lazer } \\
\text { Recreaçąa } \\
\end{array}$ & $\begin{array}{c}\text { Urb. } \\
\text { Residencial } \\
\end{array}$ & $\begin{array}{c}\text { Urb. } \\
\text { Misto } \\
\end{array}$ & $\begin{array}{c}\text { Urb. } \\
\text { Comercial } \\
\end{array}$ & $\begin{array}{c}\text { Urb. } \\
\text { Industrial }\end{array}$ & Total \\
\hline 3.00 & 4.46 & 0.00 & 0.00 & 0.00 & 0.01 & 0.00 & 0.00 & 4.47 \\
\hline 3.50 & 7.43 & 0.00 & 0.00 & 0.00 & 0.14 & 0.00 & 0.00 & 7.57 \\
\hline 4.00 & 15.19 & 0.00 & 0.00 & 0.00 & 0.22 & 0.00 & 0.01 & 15.42 \\
\hline 4.50 & 28.17 & 0.00 & 0.00 & 0.00 & 0.30 & 0.00 & 0.02 & 28.49 \\
\hline 5.00 & 99.79 & 0.00 & 0.00 & 0.00 & 0.53 & 0.00 & 0.03 & 100.36 \\
\hline 5.50 & 194.81 & 0.00 & 0.00 & 0.11 & 0.73 & 0.00 & 0.06 & 195.70 \\
\hline 6.00 & 354.64 & 0.00 & 0.00 & 1.34 & 1.48 & 0.00 & 0.11 & 357.57 \\
\hline 6.50 & 644.84 & 0.04 & 0.19 & 3.37 & 2.50 & 0.00 & 0.25 & 651.20 \\
\hline 7.00 & 860.38 & 1.54 & 4.07 & 6.70 & 16.63 & 0.00 & 1.95 & 891.27 \\
\hline 7.50 & 978.27 & 7.13 & 11.19 & 10.74 & 28.91 & 0.00 & 5.24 & 1041.47 \\
\hline 8.00 & 1033.01 & 16.24 & 16.73 & 23.29 & 50.27 & 0.25 & 7.28 & 1147.07 \\
\hline 8.50 & 1079.86 & 22.81 & 17.13 & 31.47 & 68.08 & 0.51 & 9.94 & 1229,79 \\
\hline 9.00 & 1115.34 & 31.66 & 18.92 & 42.04 & 86.03 & 0.87 & 10.54 & 1305.39 \\
\hline 9.50 & 1128.37 & 42.14 & 20.23 & 49.42 & 100.51 & 2.11 & 10.95 & 1353.74 \\
\hline 10.00 & 1138.30 & 65.23 & 21.28 & 57.85 & 108.70 & 4.71 & 11.73 & 1407.80 \\
\hline
\end{tabular}

\section{Simulação do Evento Ocorrido entre 22 e 29 de Setembro de 2007}

A inundação de setembro de 2007, com pico no dia 25, foi o evento escolhido para a simulação da dinâmica das águas sobre o município de Montenegro, em virtude da sua alta magnitude e da atualidade de sua ocorrência. Esse episódio de inundação foi monitorado de hora em hora pela TANAC S.A, na régua instalada no rio Caí, nos fundos da indústria, no período compreendido entre o dia 22/09/2007 (às 8h) ao dia 29/09/2007 (às 0h). Esses dados permitiram a modelagem com maior realismo da dinâmica de inundação.

As cotas atingidas pela água na TANAC S.A foram compatibilizadas com as cotas da estação Passo do
Montenegro, e em seguida, extrapoladas para toda a área de estudo, baseando-se no modelo de variação da lâmina d'água apresentado no subitem 3.6.

A simulação do período monitorado (22/09 à 29/09) é retratada em intervalo de tempo de $8 \mathrm{~h}$, pelas Figuras 10 a 13, às quais ilustram toda a dinâmica de inundação (avanço e retração das águas). Para ampliar o detalhamento e melhorar a visualização, fez-se um recorte da área modelada na porção mais densamente ocupada do município de Montenegro.

Na Figura 11 (A e B) as setas identificam as direções preferenciais do avanço da inundação sobre o recorte da área urbana. Observa-se que nas primeiras horas do dia 24/09/2007, entre 0h e 8h (Fig. 10-F e 11-A) a lâmina d'água começa a inundar a área urbana de Montenegro, com fluxo preferencial nas direções nordeste e noroeste. No cenário posterior (Fig. 11-B), às 16h do mesmo dia, as águas do rio Caí já inundam uma significativa parcela da cidade. O pico da inundação ocorreu próximo ao instante retratado na Figura $11-\mathrm{C}(25 / 09$, à $0 \mathrm{~h})$, precisamente à $1 \mathrm{~h}$ do dia 25 de setembro $(8,70 \mathrm{~m})$.

No evento simulado, a retração da água ocorreu muito mais lentamente do que o avanço da inundação sobre a área modelada. Nas 36 horas que antecederam o pico da inundação, o nível das águas aumentou aproximadamente $3 \mathrm{~m}$. Após o pico, foram necessárias $96 \mathrm{~h}$ para a redução do nível em $3 \mathrm{~m}$. Isso significa que a retração das águas foi 2,67 vezes mais demorada que o avanço.

O dia 24 de setembro foi que apresentou o maior aumento no nível do rio $(2,03 \mathrm{~m})$, variando de $6,65 \mathrm{~m}$ a $8,68 \mathrm{~m}$. No dia anterior (23), esse aumento foi um pouco menor, cerca de $1,9 \mathrm{~m}$. O intervalo de tempo entre as $8 \mathrm{~h}$ e $16 \mathrm{~h}$ do dia 24 de setembro se destaca como o de maior variação no nível do rio Caí, em torno de 1,05m em apenas 8 horas, surpreendendo a população pela rapidez do avanço das águas (ver Figuras 11-A e 11-B).

De acordo com a simulação realizada, mesmo depois de 96 horas do pico da inundação, havia alguns locais inundados na área urbana do município (Fig. 13-C). Considerando todo período de inundação, muitas áreas permaneceram mais de 100 horas (cerca de 4 dias) sob as águas do rio Caí. 

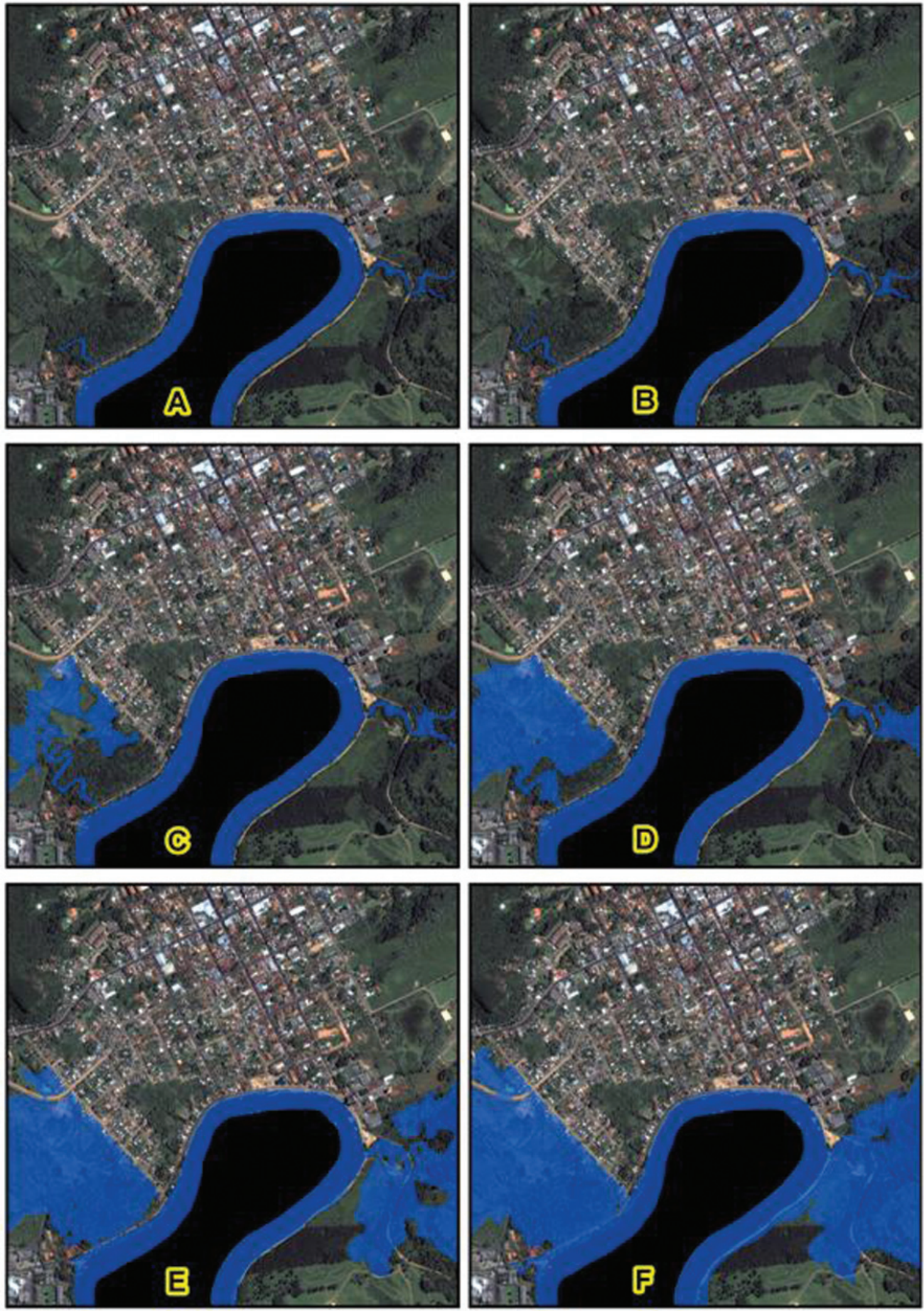

Figura 10 - Simulação da inundação de setembro de 2007, centro da área urbana de Montenegro/RS: A) 22/09/2007, às 8h (cota 3,96m); B) 22/09/2007, às 16h (cota 4,18m); C) 23/09/2007, à Oh (cota 4,75m); D) 23/09/2007, às 8h (cota 5,40m); E) 23/09/2007, às 16h (cota 6,07m); F) 24/09/2007, à 0h (cota 6,65m). 

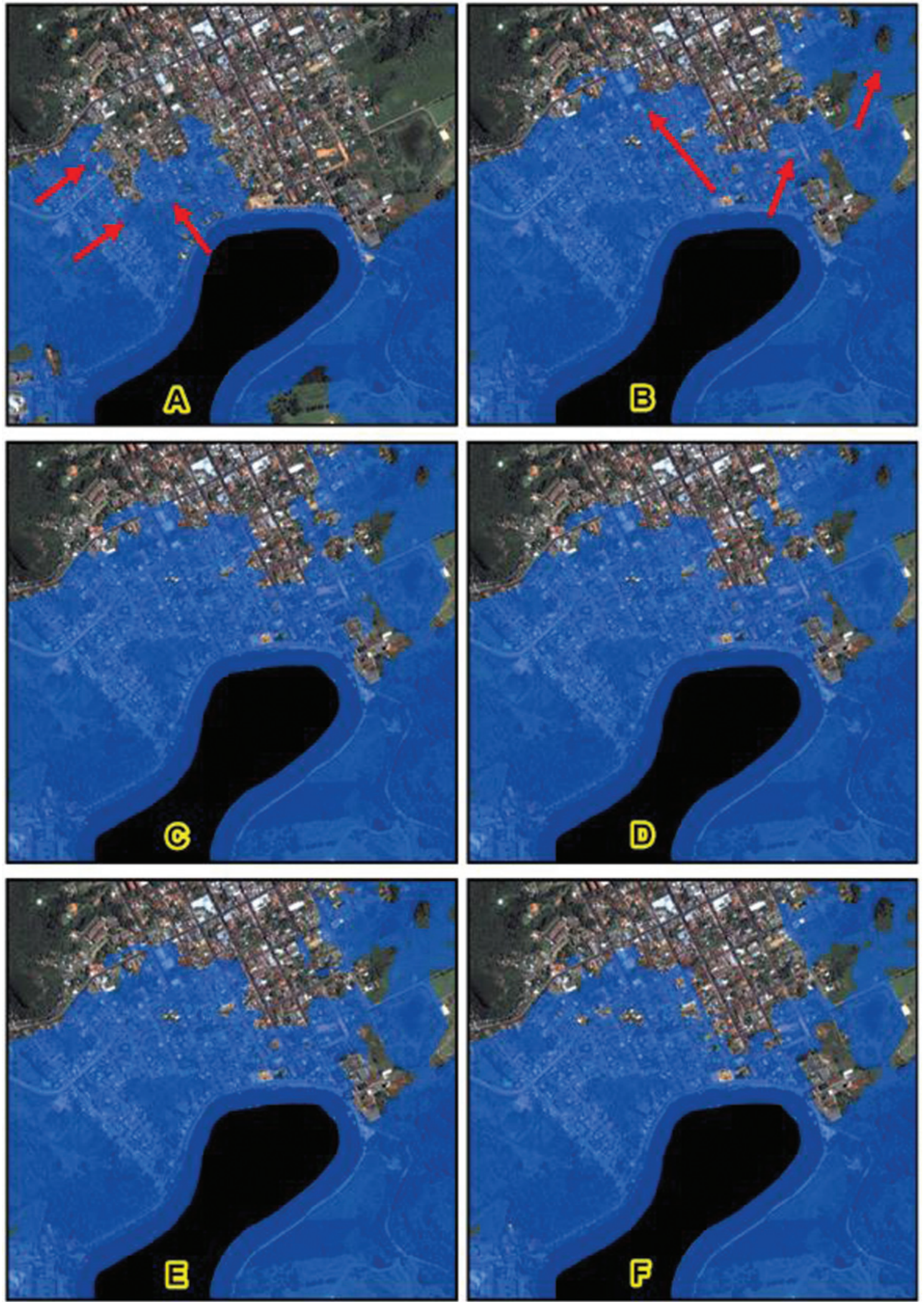

Figura 11 - Simulação da inundação de setembro de 2007, centro da área urbana de Montenegro/RS: A) 24/09/2007, às 8h (cota 7,37m); B) 24/09/2007, às 16h (cota 8,42m); C) 25/09/2007, à Oh (cota 8,68m); D) 25/09/2007, às 8h (cota 8,63m); E) 25/09/2007, às 16h (cota $8,42 \mathrm{~m})$; F) 26/09/2007, à $0 \mathrm{~h}(\operatorname{cota} 8,16 \mathrm{~m})$. 

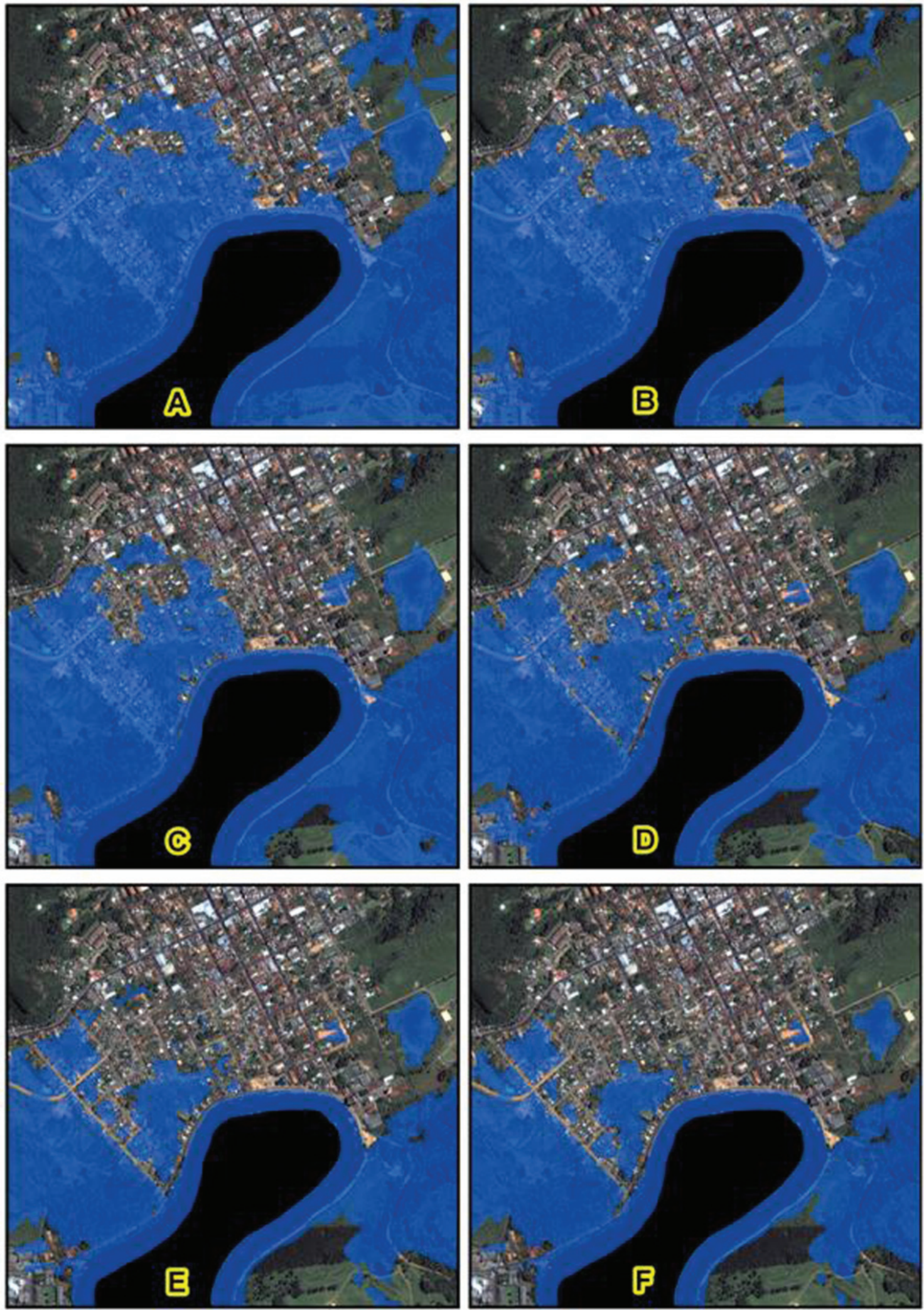

Figura 12 - Simulação da inundação de setembro de 2007, centro da área urbana de Montenegro/RS: A) 26/09/2007, às 8h (cota 7,85m); B) 26/09/2007, às 16h (cota 7,55m); C) 27/09/2007, à 0h (cota 7,30m); D) 27/09/2007, às 8h (cota 7,00m); E) 27/09/2007, às 16h (cota 6,73m); F) 28/09/2007, à Oh (cota 6,51m). 

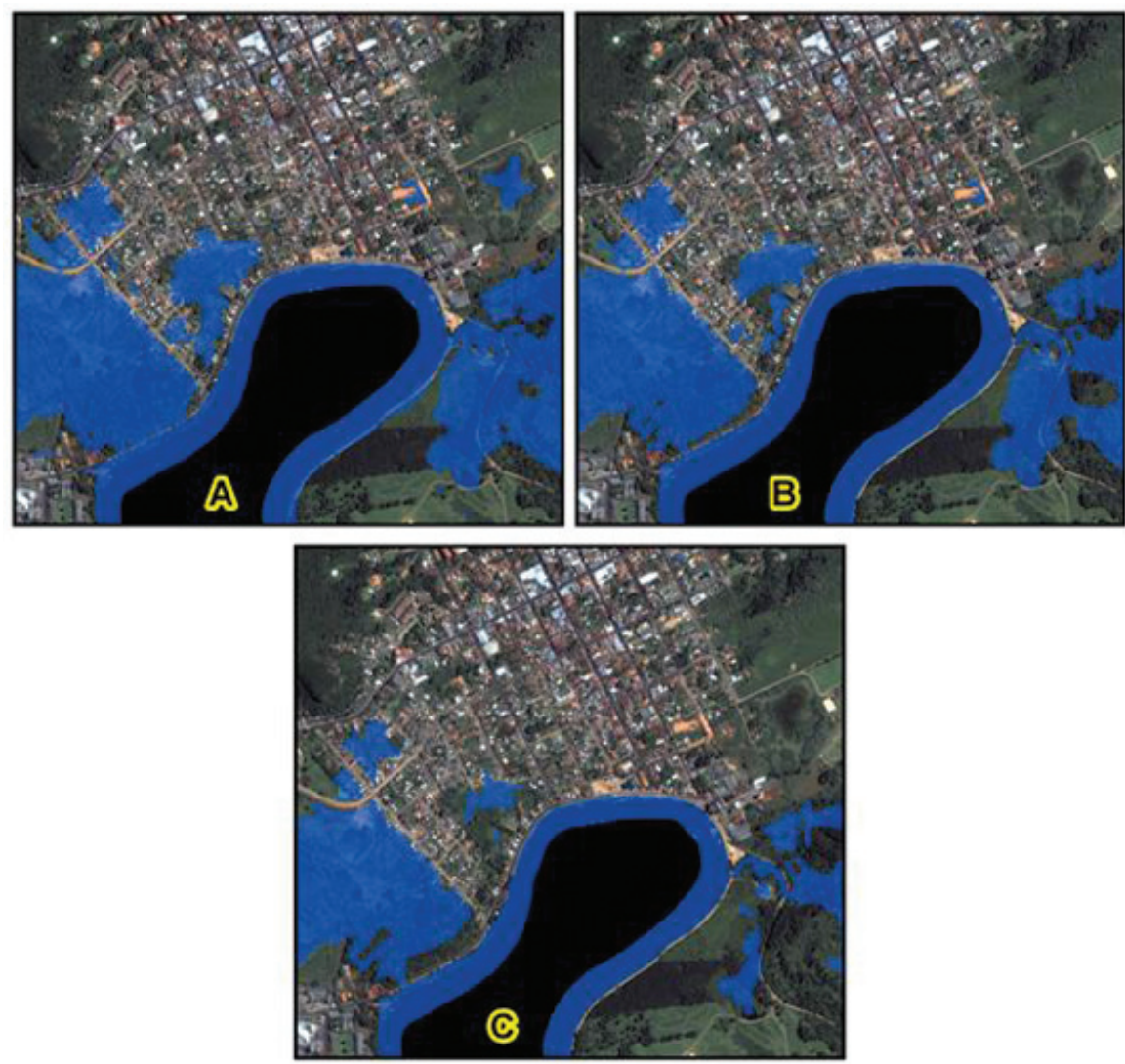

Figura 13 - Simulação da inundação de setembro de 2007, centro da área urbana de Montenegro/RS: A) 28/09/2007, às 8h (cota 6,25m); B) 28/09/2007, às 16h (cota 5,96m); C) 29/09/2007, à Oh (cota 5,68m).

Na Figura 14, observa-se o tempo sob a inundação das áreas atingidas pelas águas no período entre 22 e 29 de setembro de 2007. Os bairros Tanac, Municipal, Industrial, Passo do Manduca e Olaria foram os que ficaram um intervalo de tempo maior sob as águas do rio Caí. A área localizada entre o Bairro Municipal e o Industrial ficou inundada em torno de $130 \mathrm{~h}$ (5 dias e 10 horas). Nas áreas úmidas, ao longo do arroio da Cria e do curso d'água ao sul do bairro Passo do Manduca, muitos locais ficaram mais de $140 \mathrm{~h}$ sob a inundação (aproximadamente seis dias).

A expressiva duração da inundação sobre áreas ocupadas pela atividade humana, em Montenegro, gera grandes prejuízos para todas as esferas da sociedade e se constitui no aspecto mais preocupante do conflito entre a população e o regime fluvial. A ocupação dessas áreas deveria ser avaliada e discutida pelos órgãos públicos competentes com a participação da comunidade, para estabelecer diretrizes que restrinjam a instalação de novos empreendimentos e transfiram gradativamente a população para áreas sem riscos de inundação.

\section{Avaliação do Modelo de Inundação}

A avaliação do modelo de espacialização das inundações em Montenegro foi realizada a partir das informações coletadas e das observações realizadas em campo. O posicionamento dos pontos de referência para a avaliação do modelo foi obtido com o auxílio de croquis e com o manuseio do aparelho receptor de sinal GPS. Adotou-se como referência para essa avaliação os limites da inundação e os registros de altura de lâmina d'água do evento ocorrido em setembro de 2007.

Ao todo, 16 pontos foram utilizados na avaliação do modelo de inundação da área de estudo em Montenegro. O erro planimétrico médio foi de apenas $9 \mathrm{~m}$, sendo que o maior erro observado obteve discrepância de $24 \mathrm{~m}$ entre o limite real e o modelado da inundação de 2007. O erro altimétrico médio obtido na modelagem da inundação de 2007 foi de $0,15 \mathrm{~m}$. Esse valor é extremamente baixo e indica que o modelo possui uma excelente precisão para espacializar as áreas atingidas pelas águas. No ponto de maior erro altimétrico, verificou-se uma diferença de $0,30 \mathrm{~m}$ entre a altura de lâmina d'água real e a modelada. Nos pontos que apresentaram a melhor precisão altimétrica, os erros observados foram de $0,05 \mathrm{~m}$ a $0,10 \mathrm{~m}$. 


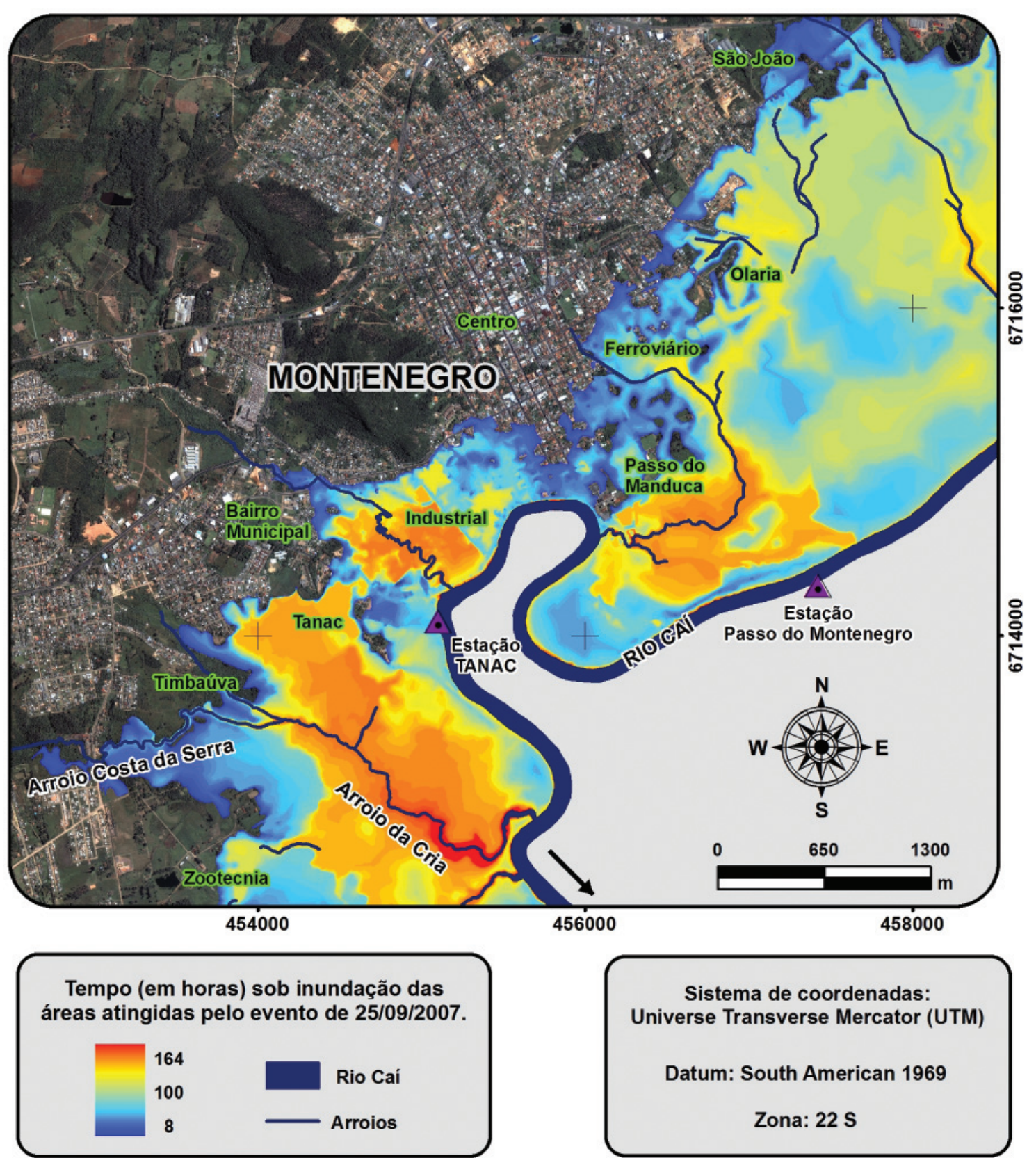

Figura 14 - Tempo sob inundação das áreas atingidas pelo evento ocorrido entre 22 e 29 de setembro de 2007, em Montenegro, RS, Brasil.

\section{Conclusões}

O modelo de previsão apresentou resultados consistentes e precisos. O resíduo médio por amostra foi de apenas $0,25 \mathrm{~m}$ e o índice de precisão oscilou entre $0,23 \mathrm{~m}$ e $0,42 \mathrm{~m}$, de acordo com os intervalos de previsão de cota, superando todas as expectativas iniciais da pesquisa. A principal justificativa para esses excelentes resultados se deve à pequena distância existente entre as estações fluviométricas utilizadas neste trabalho, aspecto que aumenta o coeficiente de correlação dos dados amostrados.
Quanto ao modelo aplicado à espacialização das áreas inundáveis em Montenegro, os resultados obtidos foram excelentes e indicaram que o método utilizado foi capaz de atender aos objetivos propostos no trabalho. O erro planimétrico nas amostras coletadas em campo foi de $9 \mathrm{~m}$ e o altimétrico, de apenas $0,15 \mathrm{~m}$.

A simulação da inundação ocorrida entre 22 e 29 de setembro de 2007 mostrou-se interessante para o entendimento da dinâmica de inundação na área de estudo. O mesmo procedimento poderá ser utilizado para modelar, dinâmica e 
espacialmente, o avanço e a retração das águas em eventos futuros, conjugando os dois modelos apresentados (de previsão e de espacialização) neste trabalho.

Tendo em vista os resultados obtidos neste estudo e a existência de um projeto de instalação de estações automáticas (com leituras de hora em hora), sugere-se a implantação de um sistema integrado de previsão e alerta de inundações para o município de Montenegro, assim que essas estações estejam em pleno funcionamento. O sistema poderia reunir os dados apresentados neste estudo, contando com a articulação dos diversos agentes envolvidos (órgãos de Defesa Civil, instituições de pesquisa e ensino, as comunidades afetadas, etc.). Uma vez implantada, essa medida deverá reduzir significativamente os prejuízos decorrentes das inundações e beneficiará os milhares de moradores afetados.

\section{Referências bibliográficas}

ALSDORF, D. E.; MELACK, J. M.; DUNNE, T.; MERTES, L. A. K.; HESS, L. L.; SMITH, L. C. Interferometric radar measurements of water level changes on the Amazon flood plain. Nature, n. 404, p. 174-177, 2000.

ANISOARA, I.; VASILE, C. GHEORGHE, S. Remote Sensing and GIS Techniques for Flood Monitoring and Damage Assessment: Study Case in Romania. BALWOIS 2010-Ohrid, Republic of Macedonia, 2010.

BATES, P. D.; HORRITT, M. S.; SMITH, C. N.; MASON, D. Integrating Remote Sensing Observations of Flood Hydrology and Hydraulic Modelling. Hydrological Processes, Vol. 11, p.1777-1795. 1997.

BATES, P. D.; MARKS, K. J.; HORRITT, M. S. Optimal use of high-resolution topographic data in flood inundation models. Hydrological Processes, 17, p.537-557. 2003.

BATES, P. D.; DE ROO, A. P. J. A simple raster-based model for flood inundation simulation. Journal of Hydrology, 236, p.54-77. 2000.

BRIVIO, P. A.; COLOMBO, R.; MAGGI, M.; TOMASONI, R. Integration of Remote Sensing Data and GIS for Accurate Mapping of Floods Areas. International Journal of Remote Sensing, London, UK: Taylor \& Francis, v. 23, n. 03, p. 429441, 2002.

BURNASH, R. J. C. The NWS river forecast system catchment modelling. In: SINGH, V. J. (Editor) Computer models of watershed hydrology. Water Resources Publications, Highlands Ranch, 1995. 1130p.

COLLISCHONN, W. Simulação hidrológica de grandes bacias. Tese de Doutorado (Engenharia de Recursos Hídricos e Saneamento Ambiental), Universidade Federal do Rio Grande do Sul (UFRGS), 2001. 270p.
COSTELLOE, J. F.; GRAYSON, R. B.; ARGENT, R. M.; MCMAHON, T. A. Modelling the flow regime of an arid zone floodplain river, Diamantina River, Australia. Environmental Modelling \& Software, n.18, p.693-703, 2003.

CPRM - COMPANHIA DE PESQUISA DE RECURSOS MINERAIS. Mapa Geológico do Estado do Rio Grande do Sul. Escala 1:750.000. Serviço Geológico do Brasil Superintendência de Porto Alegre. 2006.

DUTTA, D.; HERATH, S.; MUSIAKE, K. A mathematical model for flood loss estimation. Journal of Hydrology, n.277, p.24-49, 2003 .

ECKHARDT, R. R. Geração de modelo cartográfico aplicado ao mapeamento das áreas sujeitas às inundações urbanas na cidade de Lajeado/RS. Dissertação (Mestrado em Sensoriamento Remoto) - Centro Estadual de Pesquisas em Sensoriamento Remoto e Meteorologia, Universidade Federal do Rio Grande do Sul, Porto Alegre, 2008.

GARROTE, L.; BRAS, R. L. A distributed model for real-time flood forecasting using digital elevation models. Journal of Hydrology, n.167, p. 279-306. 1995.

HAILE, A. T.; RIENTIES, T. H. M. Effects of LIDAR DEM resolution in flood modeling: a model sentitivity study for the city of Tegucigalpa, Honduras. ISPRS WG III/3, III/4, V/3 Workshop "Laser Scanning 2005", Enschede, Netherlands, September 12-14, 2005. p.168-173, 2005.

HORRITT, M. S.; BATES, P. D. Evaluation of 1D and 2D numerical models for predicting river flood inundation. Journal of Hydrology, n.268, p.87-99, 2002.

HUTCHINSON, M. F. A new method for gridding elevation and streamline data with automatic removal of pits. Journal of Hydrology 106, p.211-232, 1989.

HUTCHINSON, M. F. Development of a continent-wide DEM with applications to terrain and climate analysis. In: Environmental Modeling with GIS, New York: Oxford University Press, p.392-399, 1993.

IBGE - INSTITUTO BRASILEIRO DE GEOGRAFIA E ESTATÍSTICA. Mapa Geomorfológico - Folha Caxias do Sul (SH.22-V-D). Escala 1:250.000. IBGE, 2003.

IMHOFF, M. L.; VERMILLION, C.; STORY, M. H.; CHOUDHURY, A. M.; GAFOOR, A. Monsoon Flood boundary delineation and damage assessment using spaceborne imaging radar and Landsat data. Photogrammetric Engineering and Remote Sensing, 53, p.405-413. 1987.

INMET - INSTITUTO NACIONAL DE METEOROLOGIA. Normais climatológicas 1961 - 1990. Instituto Nacional de Meteorologia, Brasília, 2009. Disponível em: $<$ http://www. inmet.gov.br/html/clima/mapas/?mapa=prec $>$. Acesso em $11 / 11 / 2009$. 
JENSEN, J. Remote sensing of environment: an Earth resource perspective. Prentice Hall, Upper Saddle River, New Jersey, 2000. 544p.

KAFLE, T. P.; HAZARIKA, M. K.; SHRESTHA, K. G.; PRATHUMCHAI, K.; SAMARAKOON, L. Integration of remote sensing and GIS with flood simulation model for flood hazard mapping in the Bagmati River, Nepal. New Technologies for Urban Safety of Mega Cities in Asia, Thailand, p.257-268, 2006.

LOUGEAY, R.; BAUMANN, P.; NELLIS, M. D. Two digital approaches for calculating the area of regions affected by the great American Flood of 1993. Geocarto International, n.9, p.53-59, 1994.

MARKS, K.; BATES, P. D. Integration of high-resolution topographic data with floodplain flow models. Hydrological Processes, 14, p.2109-2122, 2000.

OVERTON, I. C. Modelling Floodplain Inundation on a Regulated River: Integrating GIS, Remote Sensing and Hydrological Models. River Research and Applications, n.21, p.991-1001. 2005.

PEUKER, T. K.; FOWLER, R. J.; LITTLE, J. J.; MARK, D. $M$. The Triangulated Irregular Network. Proceedings of the International Symposium on Cartographic and Computing: Applications in Health and Environment (Auto Carto 4), v.2, p.96-103, 1979.

QI, S.; BROWN, D. G.; TIAN, Q.; JIANG, L.; ZHAO, T.; BERGEN, K. M. Inundation Extent and Flood Frequency Mapping Using LANDSAT Imagery and Digital Elevation Models. GIScience \& Remote Sensing, 46, n.1, p.101-127. 2009.

ROSENQVIST, A.; BIRKETT, C. M. Evaluation of JERS-1 SAR mosaics for Hydrological Applications in the Congo River Basin. International Journal of Remote Sensing, London, UK: Taylor \& Francis, v.23, n.07, p.1283-1302, 2002.
SCHULT, S. I. M.; PINHEIRO, A. Ocupação e Controle das Áreas Urbanas Inundáveis. In: Enchentes na Bacia do Itajaí: 20 Anos de Experiências. 1 ed., Blumenau: FURB, v. 1, p.173190, 2003.

SILVA, A. B. Sistemas de Informações Geo-referenciadas: conceitos e fundamentos. Campinas: Unicamp, 1999. 236p.

SMITH, L. C. Satellite remote sensing of river inundation area, stage, and discharge: a review. Hydrological Processes, v. 11, p.1427-1439, 1997.

TOWNSEND, P. A.; WALSH, S. J. Modeling floodplain inundation using an integrated GIS with radar and optical remote sensing. Geomorphology, v. 21, p.295-312, 1998.

TUCCI, C. E. M.; BERTONI, J. C. (Org). Inundações urbanas na América do Sul. Porto Alegre: Associação Brasileira de Recursos Hídricos, 2003.

VITTE A. C.; GUERRA, A. J. T. (Org). Reflexões sobre a geografia física no Brasil. Rio de Janeiro: Bertrand Brasil, 2004. 280p.

VÖRÖSMARTY, C. J.; MOORE, B.; GRACE, A.; PETERSON, B. J.; RASTETTER, E. B.; MELILLO, J. Distributed parameter models to analyze the impact of human disturbance of the surface hydrology of a large tropical drainage basin in southeastern Africa. Hydrology for the water management of large river basins. IAHS Publication n. 201. Proceedings of the Vienna Symposium, p.233-244, 1991.

WAHBA, G. Spline models for Observational data. Paper presented at CBMS-NSF Regional Conference Series in Applied Mathematics. Philadelphia: Soc. Ind. Appl. Maths, 1990.

WOLLMANN C. A. A gênese climática das enchentes na Bacia Hidrográfica do Rio Caí. Trabalho de Conclusão (Bacharelado em Geografia). Universidade Federal de Santa Maria (UFSM), 2008.

YANG, X.; RYSTEDT, B. Predicting Flood Inundation and Risk Using GIS and Hydrodynamic Model: A Case Study at Eskilstuna, Sweden. Indian Cartographer, p.183-191, 2002. 